UNIVERZA V LJUBLJANI

PEDAGOŠKA FAKULTETA

DRUGOSTOPENJSKI MAGISTRSKI ŠTUDIJSKI PROGRAM POUČEVANJE, PREDMETNO POUČEVANJE

Dejan Ozebek

\title{
Gelfond-Schneiderjev izrek
}

\author{
Magistrsko delo
}

Ljubljana, 2021 

UNIVERZA V LJUBLJANI

PEDAGOŠKA FAKULTETA

DRUGOSTOPENJSKI MAGISTRSKI ŠTUDIJSKI PROGRAM POUČEVANJE, PREDMETNO POUČEVANJE

Dejan Ozebek

\title{
Gelfond-Schneiderjev izrek
}

\author{
Magistrsko delo
}

Mentor: izr. prof. dr. Marko Slapar

Somentor: doc. dr. Luka Boc Thaler

Ljubljana, 2021 



\section{Zahvala}

V prvi vrsti se zahvaljujem mentorju izr. prof. dr. Marku Slaparju in somentorju doc. dr. Luku Bocu Thalerju za vse popravke in strokovno pomoč ter nasvete, ki sta mi jih nudila med pisanjem magistrskega dela.

Zahvalil bi se tudi prijateljem, ki so me tako ali drugače v času izdelave dela podpirali: s pomočjo pri oblikovanju magistrske naloge, z lektoriranjem ali pa kar tako.

Poleg tega se zahvaljujem tudi sestri Tadeji in staršem, ki so me vsa leta študija finančno in psihično podpirali pri delu in hkrati motivirali, da sem vztrajal.

Nenazadnje pa bi se rad zahvalil svoji gimnazijski profesorici matematike Ireni Verdnik, ki me je prva navdušila za matematiko in brez katere zdaj ne bi bil tam, kjer sem.

Hvala vsem! 



\section{Povzetek}

V magistrskem delu dokažemo iracionalnosti števil $e, \pi^{2}$ in $\sqrt[n]{m}$, kjer $m, n \in \mathbb{N}$ in $\sqrt[n]{m} \notin \mathbb{N}$, ki potekajo s protislovjem. Poleg tega dokažemo tudi transcendentnost števil $e$ in $\pi$, ki imata nekoliko različen potek dokaza, saj se dokaz transcendentnosti števila $\pi$ posluži tudi teorije elementarnih simetričnih polinomov. V zadnjem poglavju predstavimo še dokaz GelfondSchneiderjevega izreka, o transcendentnosti števil oblike $\alpha^{\beta}$, kjer je $\alpha \neq 0,1$ in $\beta$ iracionalno število. Gre namreč za enega redkih zapisov dokaza Gelfond-Schneiderjevega izreka v slovenskem jeziku, saj se ta pojavi le še v diplomskem delu iz leta 1978 [6] ]. Ob koncu še naštejemo nekaj posledic tega izreka in hkrati navedemo nekaj avtorjev, ki so nadaljevali z raziskovanjem transcendentnih števil.

Ključne besede: algebraična števila, transcendentna števila, Gelfond-Schneiderjev izrek.

\section{Abstract}

In this masters thesis we prove by contradiction the irrationality of the numbers $e, \pi^{2}$, and $\sqrt[n]{m}$, where $m, n \in \mathbb{N}$ and $\sqrt[n]{m} \notin \mathbb{N}$. Alongside we also prove the transcendence of the numbers $e$ and $\pi$, which have distinctly different proofs, as the proof for the transcendence of the number $\pi$ makes use of the theory of elementary symmetric polynomials. In the last chapter, we also prove the main theorem of this work, which is the Gelfond-Schneider theorem on the transcendence of numbers of the form $\alpha^{\beta}$, where $\alpha \neq 0,1$ and $\beta$ is irrational. This work is one of the rare translations of this theorem in Slovene; the only other translation appears in an undergraduate thesis from 1978 [6]. We conclude the thesis by listing several consequences of the theorem and a number of authors who advanced the work in transcendental number theory.

Keywords: algebraic numbers, transcendental numbers, Gelfond-Schneider theorem. 



\section{Kazalo}

\section{Povzetek}

1 Uvod 1

2 Uvodna teorija 3

$2.1 \quad$ Racionalnost, iracionalnost in transcendentnost števil . . . . . . . . . . . . 3

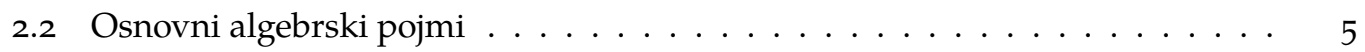

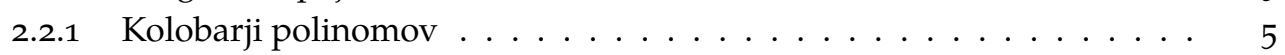

2.2 .2 Razširitve polj . . . . . . . . . . . . . . . . . . . . . 10

2.3 Analitične metode . . . . . . . . . . . . . . . . . 12

\begin{tabular}{|llr}
\hline 3 & Iracionalnost določenih števil & 17
\end{tabular}

3.1 Iracionalnost števil $\sqrt[n]{m} \ldots \ldots \ldots \ldots \ldots \ldots \ldots$

3.2 Iracionalnost števila $e^{n} \ldots \ldots \ldots \ldots \ldots \ldots \ldots$

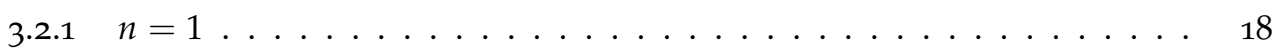

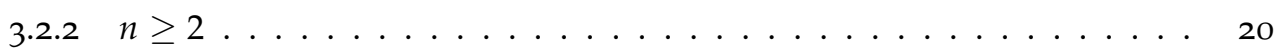

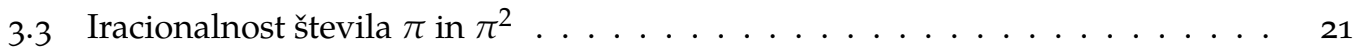

4 \begin{tabular}{|lll}
\hline & Transcendentnost določenih števil & 23
\end{tabular}

4.1 Transcendentnost števila $e \ldots \ldots \ldots \ldots \ldots \ldots . \ldots \ldots \ldots$

4.2 Transcendentnost števila $\pi \ldots \ldots \ldots$. . . . . . . . . . . . . . 26

4.3 Gelfond-Schneiderjev izrek $\ldots \ldots \ldots \ldots \ldots \ldots$. . . . . . . . . . . . . . . . 32

$4.3 .1 \quad$ Primer uporabe Gelfond-Schneiderjevega izreka . . . . . . . . . . 40

\begin{tabular}{|lll}
5 & Zaključek & 43
\end{tabular}

\begin{tabular}{ll}
\hline Literatura & 43
\end{tabular} 



\section{Uvod}

Študij iracionalnih in algebraičnih števil spada pod matematično disciplino teorije števil. Algebraično število stopnje $d$ je rešitev (ničla) nekega nerazcepnega polinoma stopnje $d \mathrm{z}$ racionalnimi koeficienti. Če ne obstaja polinom z racionalnimi koeficienti, da bi bilo dano število njegova ničla, rečemo, da je število transcendentno. V času Pitagore so poznali le cela števila in racionalna števila (ulomke). Četudi so vedeli za obstoj števila $\sqrt{2}$, so trdili, da iracionalna števila ne obstajajo. Vprašanja o transcendentnosti števil (in njihovem obstoju) so se pojavila že Eulerju leta 1748, ko je Euler sam postavil domnevo, da število $\log _{a} b$ ni algebraično (torej je transcendentno) za racionalni števili $a$ in $b$, pri čemer število $b \neq a^{c}$ za neko racionalno število $c$. Eulerjeva domneva je ostala neodgovorjena vse do Josepha Liouvilla, ki je v 20. stoletju uspel dokazati obstoj števil, ki niso algebraična. Kasneje je prav tako Liouville postavil potreben pogoj, da je število algebraično in tako tudi zadosten pogoj, da je število transcendentno. Osnova njegove metode je bila aproksimacija različnih števil $\mathrm{z}$ racionalnimi števili. Liouville je odkril, da so algebraična števila slabo aproksimabilna $\mathrm{z}$ racionalnimi števili. Iz tega potem seveda sledi, da je število transcendentno, če ga je mogoče dobro aproksimirati z racionalnimi števili. Pokazal je, da za poljubno algebraično število $a$ stopnje $d \geq 2$ in dan poljuben $\epsilon>0$ velja, da izrazu

$$
\left|a-\frac{p}{q}\right|<\frac{1}{q^{d+\epsilon}}
$$

ustreza le končno mnogo racionalnih števil $\frac{p}{q}$. Ta pogoj je mogoče uporabiti za dokaz transcendentnosti števila, a je postopek zahteven. Kasneje je več matematikov nadaljevalo Liouvillovo delo, eksponent $\mathrm{v}$ izrazu pa je bil posledično zmanjšan $\mathrm{z} d+\epsilon$ na $\frac{d}{2}+1+\epsilon$ in nenazadnje na $2+\epsilon$ leta 1955. Slednji rezultat je danes znan kot Thue-Siegel-Rothov izrek. Tu se Liouvillova zgodba z aproksimacijo nekako zaključi, saj so kasneje drugi matematiki razvili drugačne načine za dokazovanje transcendentnosti števil.

Za dokaz transcendentnosti števil je Hermite leta 1875 razvil metodo z uporabo pomožnih funkcij. Njegovo delo je nadaljeval Lindemann, ki je v 1880-ih letih dokazal, da je število $e^{\alpha}$ transcendentno za vsa neničelna algebraična števila $\alpha$. Kasneje je Weierstrass njuno delo še posplošil do rezultata, ki je danes znan kot Lindemann-Weierstrassov izrek.

S tem nazadnje prispemo do leta 1900, ko je David Hilbert na konferenci predstavil skupek nerešenih problemov (nekateri so nerešeni še danes). Sedmi med njimi je glavna tema tega magistrskega dela. Sedmi problem namreč pravi:

DOMNEVA 1.1 Naj bo $a \neq 0,1$ in naj bo $b$ iracionalno število. Potem je $a^{b}$ transcendentno število.

Na to domnevo sta pritrdilno odgovorila Alexander Gelfond in Theodor Schneider leta 1934. Dokaz njunega rezultata, ki je danes znan kot Gelfond-Schneiderjev izrek, bo predstavljen v tej 
magistrski nalogi. Ob koncu magistrskega dela bodo predstavljene še nekatere posledice izreka skupaj z nekaj primeri uporabe in kratkim opisom nadaljevanja proučevanja transcendentnih števil. 


\section{Uvodna teorija}

2.1 Racionalnost, iracionalnost in transcendentnost števil

V tem poglavju naštejemo nekaj potrebnih definicij in izrekov, ki jih bomo implicitno ali pa direktno potrebovali $\mathrm{v}$ dokazih iracionalnosti in transcendentnosti določenih števil tekom magistrskega dela. Za ta namen najprej naštejemo osnovne definicije iz teorije števil za racionalna in iracionalna števila, nato pa še za algebraična in transcendentna števila.

DEFINICIJA 2.1 (RACIONALNO ŠTEVILO) Za poljubno število $a=\frac{p}{q}$ pravimo, da je racionalno, če ga je mogoče zapisati kot razmerje med dvema celima številoma $p, q \in \mathbb{Z}$. Množico vseh racionalnih števil označimo z $Q$. Za števila, ki niso racionalna, pravimo, da so iracionalna.

Pri dokazovanju iracionalnosti se bomo pogosto oprli na naslednji izrek:

IZREK 2.2 (OSNOVNI IZREK TEORIJE ŠTEVIL) Ne obstaja celo število $a$, za katerega bi veljalo $0<a<1$.

Dokaz zgornjega izreka je bralcu dostopen $\mathrm{v}$ [5] in je posledica aksiomatske vpeljave naravnih števil s pomočjo Peanovih aksiomov.

Kot tipičen primer iracionalnega števila poznamo število $\sqrt{2}$, za katerega je večinoma že $\mathrm{v}$ srednji šoli predstavljen elementaren dokaz te trditve, ki ga zapišemo tudi $\mathrm{v}$ tem delu. Predpostavimo, da je $\sqrt{2}=\frac{a}{b}$ racionalno število, kjer sta $a, b$ tuji si celi števili in $b \neq 0$. Posebej ne moreta biti $a, b$ obe sodi števili, saj si potem ne bi mogli biti tuji. Iz naših predpostavk potem sledi:

$$
\begin{aligned}
\sqrt{2} & =\frac{a}{b} \\
2 & =\frac{a^{2}}{b^{2}} \\
a^{2} & =2 b^{2}
\end{aligned}
$$

Iz tega sledi, da je kvadrat števila $a$ sodo število, iz česar pa sledi, da mora biti tudi $a$ sodo število, saj bi bil $a^{2}$ lih, če bi bil $a$ lih.

Če pa je $a$ sodo število, ga lahko zapišemo kot $a=2 k$ za neko število $k$. $S$ tem sedaj nadomestimo ustrezna mesta $\mathrm{v}$ zgornjih enačbah:

$$
\begin{aligned}
(2 k)^{2} & =2 b^{2} \\
4 k^{2} & =2 b^{2} \\
2 k^{2} & =b^{2}
\end{aligned}
$$

Iz tega sledi, da je $b^{2}$ sodo in torej tudi $b$ sodo število. $S$ tem smo prišli do protislovja, saj smo predpostavili, da sta $a, b$ tuji si števili in je ulomek $\frac{a}{b} \mathrm{v}$ celoti okrajšan. Dokaz za iracionalnost 
števil $\sqrt{n}$, kjer $n$ ni kvadratno število, bi s primernimi popravki potekal povsem na enak način. Sedaj nadaljujemo $\mathrm{z}$ definicijama algebraičnih in transcendentnih števil.

Definicija 2.3 (Polinom S CELOŠTEVILSKIMI KOEFICIENTI) Naj bo $p(x)$ polinom stopnje $\operatorname{deg}(p)=$ $d$. Rečemo, da je $p(x)$ polinom s celoštevilskimi koeficienti, če ga lahko zapišemo kot:

$$
p(x)=c_{d} x^{d}+c_{d-1} x^{d-1}+c_{d-2} x^{d-2}+\cdots+c_{2} x^{2}+c_{1} x+c_{0}
$$

kjer so $c_{i} \in \mathbb{Z} \quad \forall i \in \mathbb{N}$. Polinomu, kjer je $c_{d}=1$, rečemo moničen polinom. Kolobar polinomov s celoštevilskimi koeficienti označimo z $\mathbb{Z}[x]$

DEFINICIJA 2.4 (ALGEBRAIČNO IN TRANSCENDENTNO ŠTEVILO) Številu $\alpha$, ki je ničla nekega polinoma $p(x)$ s celoštevilskimi koeficienti (torej $p(\alpha)=0$ ), rečemo algebraično število. Številu, ki ni rešitev nobenega polinoma s celoštevilskimi koeficienti, rečemo transcendentno število. Če je algebraično število rešitev moničnega polinoma, pravimo temu številu algebraično celo število.

PRIMER 2.5 (CELA ŠTEVILA IN RACIONALNA ŠTEVILA) Tako cela števila kot tudi racionalna števila so vsa algebraična. Poljubno celo število $a \in \mathbb{Z}$ je ničla polinoma $p(x)=x-a$, ki ima celoštevilske koeficiente. Po definiciji je torej $a$ tudi algebraično celo število.

Po drugi strani imamo racionalno število $\frac{b}{c} \in \mathbb{Q}$, ki je prav tako algebraično, saj je ničla polinoma $q(x)=c x-b$. Ker ima ta polinom vodilni koeficient $c \neq 1$, število $\frac{b}{c}$ ni algebraično celo število.

PRIMER 2.6 (ك̌TEVILO $\sqrt{-1}=i$ ) Kompleksno število $i$ je prav tako algebraično celo število, saj je ničla moničnega kvadratnega polinoma $r(x)=x^{2}+1$.

Množico vseh algebraičnih števil označimo tudi z $\mathbb{A}$. Množica vseh algebraičnih števil je števno neskončna, saj jo lahko predstavimo kot števno unijo števnih množic: množica polinomov s celoštevilskimi koeficienti fiksne stopnje $d$ je števna, vsak tak polinom pa ima največ $d$ različnih ničel. Ker je $\mathbb{R}$ neštevna množica, mora biti množica vseh transcendentnih števil $\mathbb{T}=\mathbb{R}-\mathbb{A}$ neštevno neskončna. Torej je večina števil, ki jih poznamo, transcendentnih.

Definicija 2.7 (Arhimedova lastnost UREJENEGA POLJA) Urejeno polje $F$ ima Arhimedovo lastnost, če za vsako pozitivno število $x \in F$ in $y \in F$, velja, da obstaja celo število $n>0$, da je $n x>y$.

IZREK 2.8 Množica realnih števil $\mathbb{R}$ ima Arhimedovo lastnost.

Izrek je posledica dejstva, da so naravna števila neomejena podmnožica realnih števil. Natančen dokaz lahko bralec med drugim najde v [4, s.14].

DEFINICIJA 2.9 (Gosta MNOŽICA) Za množico $S$ realnih števil pravimo, da je povsod gosta na intervalu, če lahko za poljubni realni števili $a<b$ s tega intervala najdemo tak $s \in S$, da velja $a<s<b$. 
IZREK 2.10 Racionalna števila so povsod gosta v realnih številih. Enako velja za iracionalna števila.

Dokaz Naj bosta $a$ in $b$ poljubni realni števili, kjer je $a<b$. Ker smo privzeli $a<b$, sledi, da $b-a>0$, torej je razlika vedno pozitivna. Za uporabo Arhimedove lastnosti si izberemo števili $b-a$ in 1 . Če je $b-a>1$, potem takoj sledi, da lahko najdemo $n>0$, da velja $n(b-a)>1$, zato predpostavimo, da je $b-a<1$. Po Izreku 2.8 lahko potem izberemo $n$, da zapišemo $n(b-a)>1$ oziroma $(b-a)>\frac{1}{n}$.

Sedaj si izberemo celo število $m \in \mathbb{Z}$, ki zadošča neenakostim $m<n b \leq m+1$, kar je ekvivalentno $\frac{m}{n}<b<\frac{m+1}{n}$. Iz tega sedaj sledi naslednje:

$$
a<b-\frac{1}{n} \leq \frac{m+1}{n}-\frac{1}{n}=\frac{m}{n}
$$

in

$$
\frac{m}{n}<b
$$

Iz tega potemtakem sledi, da je $\frac{m}{n}$ racionalno število, ki leži med $a$ in $b$. S tem je dokazan prvi del našega izreka. Za drugi del je postopek podoben: ponovno moramo izbrati primeren $k \in \mathbb{Z}^{+}$(po Izreku 2.8 to lahko storimo). Vemo, da je $a<\frac{m}{n}$, iz česar potem za izbran $k$ sledi

$$
k\left(b-\frac{m}{n}\right)>\sqrt{2}
$$

$S \sqrt{2}$ zagotovimo, da bo dobljeno število iracionalno. Iz prejšnje neenakosti potem sledi:

$$
b>\frac{\sqrt{2}}{k}+\frac{m}{n}>\frac{m}{n}>a .
$$

Potemtakem je $\frac{\sqrt{2}}{k}+\frac{m}{n}$ iracionalno število, ki leži med $a$ in $b$, in je s tem dokazan še drugi del izreka.

\subsection{Osnovni algebrski pojmi}

V tem razdelku si bomo ogledali osnovne algebrske pojme, ki jih bomo uporabljali v nadaljevanju. Ključnega pomena bodo predvsem razširitve polj, kolobar polinomov in kvocientni kolobar po idealu. Predpostavljeno je, da ima bralec nekaj osnov iz abstraktne algebre in so mu znane osnovne definicije grup, komutativnosti, asociativnosti ter binarnih operacij in z njimi povezanih trditev. Tekom poglavja znotraj besedila zapišemo tudi nekaj tipičnih primerov. Za ta del poglavja kot glavni vir vzamemo [3].

\subsubsection{Kolobarji polinomov}

DEFINICIJA 2.11 (КоLовARJi) Kolobar $(R,+, *)$ je množica $R$, opremljena z dvema binarnima operacijama + in $*$, ki jima pravimo seštevanje in množenje in sta definirani nad $R$, da veljajo naslednji aksiomi: 
1. $(R,+)$ je Abelova grupa, kar pomeni:

- $(a+b)+c=a+(b+c)$ za vsa $a, b, c \in R$ (asociativnost)

- $a+b=b+a$ za vsa $a, b \in R$ (komutativnost)

- Obstaja element $0 \in R$, da je $a+0=a$ za vse $a \in R$ ( 0 je enota za seštevanje)

- Za vsak $a \in R$ obstaja element $-a \in R$, tako da je $a+(-a)=0$ ( $-a$ je inverz $a$ za seštevanje)

2. $(R, *)$ je polgrupa, kar pomeni:

- $(a * b) * c=a *(b * c)$ za vse $a, b, c \in R(*$ je asociativna operacija $)$

3. Za vse $a, b, c \in R$ veljata levi distribucijski zakon $a *(b+c)=(a * b)+(a * c)$ in desni distribucijski zakon $(a+b) * c=(a * c)+(b * c)$.

Če je množenje v zgornji definiciji kolobarja še komutativno, potem takemu kolobarju rečemo komutativni kolobar. Če ima ta kolobar še multiplikativno enoto $1,1 \neq 0$, tako da velja $1 \times a=a \times 1=a$ za vse elemente $a$ iz kolobarja, potem takemu kolobarju rečemo kolobar $\mathrm{z}$ enoto. Zgornji definiciji ustreza veliko podmnožic, ki jih med šolanjem večkrat srečamo. Veljajo namreč za poljubno podmnožico kompleksnih števil, ki je grupa za običajno seštevanje in je zaprta za običajno množenje. Potemtakem so vsi $(\mathbb{Z},+, \times),(\mathbb{Q},+, \times),(\mathbb{R},+, \times)$ in $(\mathbb{C},+, \times)$ komutativni kolobarji z enoto.

DEFINICIJA 2.12 (IDEAL KOLOBARJA) Podkolobar $N$ kolobarja $R$, ki zadošča lastnostma:

- $a N \subseteq N$ za vse $a \in R$

- $N b \subseteq N$ za vse $b \in R$,

imenujemo ideal.

Če imamo torej ideal $N$ kolobarja $R$, aditivni odseki ideala $N$ sestavljajo kolobar $R / N=$ $\{a+N ; a \in K\}$, ki mu rečemo kvocientni kolobar po $N$ (oziroma kvocientni kolobar kolobarja $R$ modulo $N$ ). V R/N sta binarni operaciji seštevanja in množenja definirani kot:

$$
(a+N)+(b+N)=(a+b)+N .
$$

in za zmnožek

$$
(a+N)(b+N)=a b+N
$$

Običajno ima kolobar $R$ identiteto. Elementu $u \in R$ rečemo enota $\mathrm{v} R$, če ima ta element multiplikativni inverz v $R$. Če je vsak neničelni element iz $R$ enota, potem rečemo, da je $R$ obseg. Če je ta obseg še komutativen, rečemo, da je $R$ polje.

DEFINICIJA 2.13 (MAKSIMALNI IDEAL) Maksimalni ideal kolobarja $R$ je ideal $M$, različen od $R$, tako da ne obstaja pravi ideal $N$ kolobarja $R$, ki bi v celoti vseboval $M$. 
S pomočjo maksimalnih idealov lahko pridobimo polja, ki so kvocientni kolobarji, kar formuliramo v naslednjem izreku:

IZREK 2.14 Naj bo $R$ komutativni kolobar z enoto. Potem je $M$ maksimalni ideal kolobarja $R$, če in samo če je kvocientni kolobar $R / M$ polje.

Dokaz Naj bo $M$ maksimalni ideal kolobarja $R$. Če je $R$ komutativni kolobar z enoto, potem je tudi $R / M$ komutativni kolobar z enoto, če $M \neq R$, kar pa je res, če je $M$ maksimalni ideal. Naj bo sedaj $(a+M) \in R / M$, kjer je $a \notin M$, tako da $a+M$ ni identiteta za seštevanje $\mathrm{v}$ $R / M$. Da pokažemo, da je $R / M$ polje, moramo pokazati, da ima $a+M$ multiplikativni inverz v R/M. Zapišemo:

$$
N=\left\{r a+\frac{m}{r} \in R, m \in M\right\} .
$$

Zgornja množica je grupa za običajno seštevanje $(N,+)$, saj velja:

$$
\left(r_{1} a+m_{1}\right)+\left(r_{2} a+m_{2}\right)=\left(r_{1}+r_{2}\right) a+\left(m_{1}+m_{2}\right),
$$

kjer je desna stran enakosti vsebovana $\mathrm{v} N$. Prav tako velja $0=0 a+0$ in $-(r a+m)=$ $(-r) a+(-m)$.

Če si ogledamo $r_{1}(r a+m)=\left(r_{1} r\right) a+r_{1} m$, vidimo, da je tudi $r_{1}(r a+m) \in N$ za $r_{1} \in R$, ker pa je $R$ komutativen kolobar, velja tudi, da je $(r a+m) r_{1} \in N$. Potemtakem je po definiciji $N$ res ideal. Vendar pa lahko vidimo, da je $a=1 a+0$, iz česar sledi, da je $a \in N$ in za $m \in M$ velja $m=0 a+m$, iz česar vidimo, da je $M$ podmnožica $N$. Torej je $N$ ideal kolobarja $R, \mathrm{ki}$ vsebuje $M$, ker je $a \in N$, vendar pa $a \notin M$. Ker pa smo predpostavili, da je $M$ maksimalen, mora veljati, da je $N=R$. Natančneje namreč imamo enoto 1 , ki pripada tudi $N$, torej $1 \in N$. Po definiciji naše množice $N$ obstajata element $b \in R$ in element $m \in M$, da je $1=b a+m$. Potemtakem:

$$
1+M=b a+M=(b+M)(a+M),
$$

iz česar pa nemudoma vidimo, da je $b+M$ multiplikativni inverz $a+M$. S tem smo torej pokazali, da je $R / M$ polje.

Obratno sedaj predpostavimo, da je $R / M$ polje, in pokažimo, da to pomeni, da je $M$ maksimalni ideal kolobarja $R$. Če je $N$ poljuben ideal kolobarja $R$, da velja $M \subset N \subset R$, in je $\gamma$ kanonični homomorfizem iz $R$ na $R / M$, potem je $\gamma[N]$ ideal kolobarja $R / M$, kjer je $\{(0+M)\} \subset \gamma[N] \subset R / M$. Vendar pa je $R / M$ polje; prej smo že povedali, da če je $R / M$ polje, ne more vsebovati pravega netrivialnega ideala. Če je torej $R / M$ polje, iz tega nujno sledi, da je $M$ maksimalni ideal.

Če je $R$ kolobar, z $R[x]$ označimo kolobar polinomov v spremenljivki $x$. Elementi iz $R[x]$ so torej formalne vsote $f(x)=a_{n} x^{n}+a_{n-1} x^{n-1}+\cdots+a_{1} x+a_{0}$, kjer so $a_{0}, a_{1}, \ldots, a_{n}$ elementi kolobarja $R$. Če je $R$ komutativni kolobar, je tudi $R[x]$ komutativen, in če ima $R$ enoto, jo ima tudi $R[x]$. Več o kolobarjih polinomov lahko najdemo v [3. s.3o8-311]. V nadaljevanju bomo običajno obravnavali le kolobarje polinomov nad polji.

DEFINICIJA 2.15 (RAZCEPNI POLINOM) Nekonstanten polinom $f(x) \in F[x]$ je razcepen nad poljem $F$, če ga je mogoče izraziti kot produkt $g(x) h(x)$ dveh polinomov $g(x) \in F[x]$ in $h(x) \in F[x]$, pri čemer imata oba polinoma nižjo stopnjo, kot je stopnja polinoma $f(x)$. Sicer rečemo, da je polinom nerazcepen. 
DEFiniciJa 2.16 (GLAVNi IDEAL) Če je $R$ komutativni kolobar z enoto in $a \in R$, potem idealu $\{r a \mid r \in R\}$ vseh večkratnikov $a$ rečemo glavni ideal, generiran z elementom $a$, označimo pa $\langle a\rangle$. Idealu $N$ kolobarja $R$ rečemo glavni ideal, če je $N=\langle a\rangle$ za nek $a \in R$. Če je vsak ideal v kolobarju glavni, rečemo, da je kolobar glavni.

Tipičen primer za zgornjo definicijo je recimo ideal $\langle x\rangle \mathrm{v} F[x]$, ki je sestavljen iz vseh polinomov v $F[x]$, ki imajo ničelni prosti člen. Če je $F$ polje in je $I$ ideal v $F[x]$, potem je $I$ generiran $\mathrm{s}$ polinomom najmanjše stopnje, ki je vsebovan $\mathrm{v} I$. To lahko enostavno dokažemo s pomočjo izreka o deljenju polinomov. Zato velja:

IZREK 2.17 Če je $F$ polje, potem je $F[x]$ glavni kolobar.

IZREK 2.18 Naj bo $F$ polje. Ideal $\langle p(x)\rangle \neq\{0\}$ kolobarja $F[x]$ je maksimalen, če in samo če je $p(x)$ nerazcepen nad $F$.

Dokaz Predpostavimo, da je $\langle p(x)\rangle \neq\{0\}$ maksimalni ideal $F[x]$. Potem velja $\langle p(x)\rangle \neq$ $F[x]$ in torej $p(x) \notin F$. Naj bo $p(x)=f(x) g(x)$ faktorizacija polinoma $p(x)$ v $F[x]$. Ker je $\langle p(x)\rangle$ maksimalni ideal $(f(x) g(x)) \in\langle p(x)\rangle$ implicira, da je $f(x) \in\langle p(x)\rangle$ ali pa $g(x) \in\langle p(x)\rangle$, saj bi v nasprotnem primeru ideal, generiran $\mathrm{s} p(x)$ in $f(x)$, strogo vseboval ideal $\langle p(x)\rangle$. Potem je bodisi $f(x)$ deljiv s $p(x)$ ali pa $g(x)$ deljiv s $p(x)$. Vendar pa potem ne moreta biti stopnji $f(x)$ in $g(x)$ manjši od stopnje $p(x)$. Potemtakem je $p(x)$ nerazcepen nad $F$.

Obratno, če je $p(x)$ nerazcepen nad $F$, predpostavimo, da je $N$ tak ideal, da velja $\langle p(x)\rangle \subset$ $N \subset F[x]$. Po Izreku 2.17 je $N$ glavni ideal, torej $N=\langle g(x)\rangle$ za nek $g(x) \in N$. Potem dejstvo, da je $p(x) \in N$, implicira, da je $p(x)=g(x) q(x)$ za nek $q(x) \in F[x]$. Vendar pa je $p(x)$ nerazcepen, kar pomeni, da je bodisi $g(x)$ ali pa $q(x)$ stopnje 0 . Če je $g(x)$ stopnje 0 torej neničelen konstanten člen $\mathrm{v} F$, potem je $g(x)$ enota $\mathrm{v} F[x]$ in torej $\langle g(x)\rangle=N=F[x]$. Če pa je $q(x)$ stopnje 0 , potem je $q(x)=c$, kjer je $c \in F$ in $\langle g(x)\rangle=(1 / c) p(x)$ element $\langle p(x)\rangle$ in potemtakem $N=\langle p(x)\rangle$. Torej ni mogoče, da je $\langle p(x)\rangle \subset N \subset F[x]$, iz česar potem sledi, da je $\langle p(x)\rangle$ maksimalen.

Definicija 2.19 (НомомоRFIZEM KolobarJeV) Naj bosta $(R,+, \times)$ in $\left(R^{\prime}, \oplus, \otimes\right)$ kolobarja. Preslikava $\phi: R \rightarrow R^{\prime}$ je homomorfizem, če za vse $a, b \in R$ veljata naslednja pogoja:

1. $\phi(a+b)=\phi(a) \oplus \phi(b)$

2. $\phi(a \times b)=\phi(a) \otimes \phi(b)$

Če je preslikava iz zgornje definicije še bijektivna, potem rečemo, da je to izomorfizem kolobarjev, in označimo $R \cong R^{\prime}$.

Sledi izrek o evalvacijskem homomorfizmu za teorijo polj, skupaj z dokazom, ki sledi skoraj nemudoma iz definicij seštevanja in množenja nad $F[x]$. Vir dokaza je [3, s.312].

IZREK 2.20 (EVALVACIJSKI HOMOMORFIZEM ZA TEORIJO POLJ) Naj bo $F$ podpolje polja $E$ in naj bo $\alpha \in E$ poljuben element iz $E$. V tem primeru naj bo $x$ spremenljivka. Preslikava $\phi_{\alpha}: F[x] \rightarrow E$, 
ki jo definiramo z naslednjim izrazom:

$$
\phi_{\alpha}\left(a_{0}+a_{1} x+\cdots+a_{n} x^{n}\right)=a_{0}+a_{1} \alpha+\cdots+a_{n} \alpha^{n},
$$

je homomorfizem. Velja, da $\phi_{\alpha}(x)=\alpha$ in da je zožitev $\phi_{F}: F \rightarrow F$ izomorfizem. Homomorfizmu $\phi_{\alpha}$ rečemo evalvacija $\mathrm{v} \alpha$.

Dokaz Preslikava $\phi_{\alpha}$ je dobro definirana, saj je neodvisna od reprezentacije našega polinoma $f(x) \in F[x]$, ki je zapisan kot končna vsota

$$
a_{0}+a_{1} x+\cdots+a_{n} x^{n}
$$

Tako končno vsoto $f(x)$ lahko $\mathrm{z}$ lahkoto spremenimo z dodajanjem ali odstranjevanjem členov $0 x^{i}$, kar pa ne vpliva na vrednost preslikave $\phi_{\alpha}(f(x))$. Naj bodo sedaj $f(x)=a_{0}+a_{1} x+$ $\ldots a_{n} x^{n}, g(x)=b_{0}+b_{1} x+\ldots b_{m} x^{m}$ in $h(x)=f(x)+g(x)=c_{0}+c_{1} x+\cdots+c_{r} x^{r}$. Potem je:

$$
\phi_{\alpha}(f(x)+g(x))=\phi_{\alpha}(h(x))=c_{0}+c_{1} \alpha+\cdots+c_{r} \alpha^{r},
$$

medtem ko je

$$
\phi_{\alpha}(f(x))+\phi_{\alpha}(g(x))=\left(a_{0}+a_{1} \alpha+\cdots+a_{n} \alpha^{n}\right)+\left(b_{0}+b_{1} \alpha+\cdots+b_{m} \alpha^{m}\right) .
$$

Po definiciji seštevanja polinomov imamo, da je $c_{i}=a_{i}+b_{i}$ in torej:

$$
\phi_{\alpha}(f(x)+g(x))=\phi_{\alpha}(f(x))+\phi_{\alpha}(g(x)) .
$$

Če si ogledamo še množenje, vidimo, da če je

$$
f(x) g(x)=d_{0}+d_{1} x+\cdots+d_{s} x^{s},
$$

potem je

$$
\phi_{\alpha}(f(x) g(x))=d_{0}+d_{1} \alpha+\cdots+d_{s} \alpha_{s}
$$

medtem ko je

$$
\left(\phi_{\alpha}(f(x))\right)\left(\phi_{\alpha}(g(x))\right)=\left(a_{0}+a_{1} \alpha+\cdots+a_{n} \alpha^{n}\right)\left(b_{0}+b_{1} \alpha+\cdots+b_{m} \alpha_{m}\right) .
$$

Po definiciji množenja polinomov $d_{j}=\sum_{i=0}^{j} a_{i} b_{j-i}$, vidimo, da je

$$
\phi_{\alpha}(f(x) g(x))=\left(\phi_{\alpha}(f(x))\right)\left(\phi_{\alpha}(g(x))\right) .
$$

Potemtakem je $\phi_{\alpha}$ homomorfizem.

Po definiciji preslikave $\phi_{\alpha}$, ki jo vrednotimo v konstantnem polinomu $a \in F[x]$, kjer je $a \in F$, dobimo, da je $\phi_{\alpha}(a)=a$, in torej $\phi_{\alpha}$ preslika $F$ izomorfno z identično preslikavo. Po definiciji preslikave $\phi_{\alpha}$ sledi, da je $\phi_{\alpha}(x)=\phi_{\alpha}(1 x)=1 \alpha=\alpha$. S tem je dokaz zaključen.

Slika zgornjega homomorfizma $\phi_{\alpha}: F[x] \rightarrow E$ je kolobar v $E$, ki ga označimo z $F[\alpha]$. Je najmanjši kolobar $\mathrm{v} E$, ki vsebuje elemente $F$ in element $\alpha$. 


\subsubsection{Razširitue polj}

DEFINICIJA 2.21 (RAZŠIRITEV POLJA) Za polje $E$ rečemo, da je razširitveno polje polja $F$, če je $F$ podpolje polja $E$. Če je polje $E$ končnodimenzionalno vektorsko polje nad $F$ stopnje $n$, potem je $E$ končna razširitev nad $F$ stopnje $n$. Stopnjo $n$ razširitve označimo z $[E: F]$.

DEFINICIJA 2.22 (ALGEBRAIČNI ELEMENT) Naj bo polje $E$ razširitev polja F. Element $\alpha \in E$ je algebraični element nad $F$, če obstaja polinom $f(x) \in F[x]$, da je $f(\alpha)=0$. Polje $E$ je algebraična razširitvev polja $F$, če je vsak element iz $E$ algebraičen nad $F$.

IZREK 2.23 Če je $E$ končna razširitev polja $F$, potem je $E$ algebraična razširitev polja $F$.

Dokaz Pokazati je treba, da je, če velja $\alpha \in E, \alpha$ algebraično nad $F$. Ker je $E$ končnodimenzionalno vektorsko polje nad $F$ in privzamemo, da je $[E: F]=n$, velja, da

$$
1, \alpha, \alpha^{2}, \ldots, \alpha^{n}
$$

niso linearno neodvisni elementi. Potemtakem mora obstajati $a_{i} \in F$, da velja

$$
a_{n} \alpha^{n}+\cdots+a_{1} \alpha+a_{0}=0,
$$

kjer niso vsi $a_{i}=0$. Potem je $f(x)=a_{n} x^{n}+\cdots+a_{1} x+a_{0}$ neničeln polinom $\mathrm{v} F[x]$ in velja, da je $f(\alpha)=0$. Torej je $\alpha$ algebraično nad $F$.

Naslednji izrek, katerega dokaz sledi neposredno iz definicij, nam definira pojem minimalnega polinoma algebraičnega elementa.

IZREK 2.24 Naj bo $E$ razširitveno polje polja $F$ in naj bo $\alpha \in E$, kjer je $\alpha$ algebraičen nad $F$. Potem obstaja nerazcepen polinom $p(x) \in F[x]$, da velja $p(\alpha)=0$. Ta polinom je enoličen do konstantnega faktorja natančno v $F$ in je minimalne stopnje $\geq 1 \mathrm{v} F[x]$ ter ima $\alpha$ za ničlo. Če je $f(\alpha)=0$ za $f(x) \in F[x]$ in $f(x) \neq 0$, potem velja, da $p(x)$ deli $f(x)$.

Če je $E$ razširitveno polje polja $F$ in je $\alpha \in E$ algebraično nad $F$, potem nerazcepni enolični (monični) polinom $p(x)$ iz Izreka 2.24 označimo z $\operatorname{irr}(\alpha, F)$. Naj bo $E$ razširitev polja $F$ in $\alpha_{1}, \ldots, \alpha_{n} \in E$. Z $F\left(\alpha_{1}, \ldots, \alpha_{n}\right)$ označimo najmanjše polje v $E$, poleg elementov iz $F$ vsebuje tudi vse elemente $\alpha_{1}, \ldots, \alpha_{n}$.

IZREK 2.25 Naj bo $E$ razširitveno polje polja $F$ in $\alpha \in E$ algebraičen nad $F$. Potem je $F[\alpha]=$ $F(\alpha)$.

Dokaz Dokazati moramo le, da je $F[\alpha]$ obseg. Naj bo $p=\operatorname{irr}(\alpha)$. Potem je $F[\alpha]=$ $F[x] /\langle p(x)\rangle$. Ker je $p$ nerazcepen, je $\langle p(x)\rangle$ maksimalni ideal in zato $F[\alpha]$ polje.

IZREK 2.26 Naj bo $E$ algebraična razširitev polja $F$. Potem obstaja končno mnogo elementov $\alpha_{1}, \ldots, \alpha_{n} \in E$, da velja $E=F\left(\alpha_{1}, \ldots, \alpha_{n}\right)$ natanko tedaj, ko je $E$ končna razširitev polja $F$.

Dokaz Če je $E$ končna razširitev in elementi $\alpha_{1}, \alpha_{2}, \ldots, \alpha_{n}$ tvorijo bazo $E$ kot vektorskega prostora nad $F$, potem je seveda $E=F\left(\alpha_{1}, \ldots, \alpha_{n}\right)$. Obratno predpostavimo, da je $E=$ 
$F\left(\alpha_{1}, \ldots, \alpha_{n}\right)$. Ker so vsi $\alpha_{i}$ algebraični elementi, za vsak indeks $i$ obstaja naravno število $n_{i}$. Potenco $\alpha_{i}^{n_{i}}$ lahko potem izrazimo kot linearno kombinacijo elementov $1, \ldots, \alpha_{i}^{n_{i-1}}$. Zato je $E$ končnodimenzionalna razširitev $F$.

IZREK 2.27 Naj bo $E$ razširitveno polje polja $F$. Potem je

$$
\overline{F_{E}}=\{\alpha \in E \mid \alpha \text { je algebraičen nad } \mathrm{F}\}
$$

podpolje polja $E$. Rečemo, da je $\overline{F_{E}}$ algebraično zaprtje polja $F \mathrm{v} E$.

Dokaz Naj bosta $\alpha, \beta \in \overline{F_{E}}$. Po zgornjem izreku je $F(\alpha, \beta)$ končna razširitev polja $F$, iz Izreka 2.23 pa sledi, da je vsak element polja $F(\alpha, \beta)$ algebraičen nad $F$, torej $F(\alpha, \beta) \subseteq \overline{F_{E}}$. Torej mora $\overline{F_{E}}$ vsebovati tudi $\alpha+\beta, \alpha \times \beta, \alpha-\beta$ in $\alpha \times \beta^{-1}=\frac{\alpha}{\beta}$ za $\beta \neq 0$. Iz tega sledi, da mora biti $\overline{F_{E}}$ podpolje polja $E$.

Če v zgornjem izreku vzamemo $F=\mathbb{R}$ in $E=\mathbb{C}$, dobimo naslednji izrek:

IZREK 2.28 Množica vseh algebraičnih števil je polje.

Če je $E$ algebraična razširitev polja $F$, potem je po definiciji vsak element iz $E$ ničla nekega polinoma iz $F[x]$. Seveda pa ni nujno, da ima vsak polinom iz $F[x]$ ničlo v $E$.

DEFiniciJa 2.29 (ALGEBRAIČNO ZAPRTJE) Polje $F$ je algebraično zaprto, če ima vsak nekonstanten polinom iz $F[x]$ ničlo v $F$.

IZREK 2.30 Polje $F$ je algebraično zaprto natanko tedaj, kadar je mogoče vsak nekonstanten polinom iz $F[x]$ razcepiti na linearne faktorje $\mathrm{v} F[x]$.

Dokaz Naj bo $F$ algebraično zaprto polje in naj bo $f(x) \in F[x]$ nekonstanten polinom. Potem ima $f(x)$ ničlo $a \in F$. Potemtakem je $x-a$ delitelj $f(x)$, torej lahko zapišemo $f(x)=$ $(x-a) g(x)$. Če je $g(x)$ nekonstanten, mora imeti ničlo $b \in F$, iz česar sledi $f(x)=(x-$ $a)(x-b) h(x)$. Če proces nadaljujemo, dobimo zmnožek linearnih faktorjev oziroma razcep $f(x) \in F[x]$. Obratno, predpostavimo, da ima vsak nekonstanten polinom $\mathrm{v} F[x]$ razcepitev na linearne člene. Če je $a x-b$ linearen faktor $f(x)$, potem je $\frac{b}{a}$ ničla polinoma $f(x)$. Torej je $F$ algebraično zaprto polje.

Vsako polje $F$ ima algebraično zaprtje, torej algebraično razširitev $\bar{F}$, ki je algebraično zaprta. Izreka tukaj ne bomo dokazovali. Za nas bo predvsem pomemben naslednji izrek, ki ga bomo dokazali v naslednjem razdelku.

IZReK 2.31 (OsNovNi IZReK ALGebre) Polje C kompleksnih števil je algebraično zaprto polje.

DEFINICIJA 2.32 (KoNJUGIRANI ELEMENTI) Naj bo $E$ algebraična razširitev polja F. Elementa $\alpha, \beta \in F$ sta si konjugirana nad $F$, če imata isti nerazcepni polinom. 
PRIMER 2.33 Dana definicija ustreza tudi definiciji kompleksnih konjugirancev nad $\mathbb{R}$. Če sta $a, b \in \mathbb{R}$ in $b \neq 0$, sta kompleksna konjugiranca $a+b i$ in $a-b i$ oba ničli polinoma $x^{2}-2 a x+a^{2}+b^{2}$, ki je nerazcepen nad $\mathbb{R}[x]$.

IZREK 2.34 (IZOMORFIZEM KONJUGIRANIH ELEMENTOV) Naj bo $F$ polje in naj bosta $\alpha$ in $\beta$ algebraična nad $F$ s stopnjo $n$ (stopnja nerazcepnega polinoma, kateremu pripadata, je $n$ ). Preslikava $\psi_{\alpha, \beta}: F(\alpha) \rightarrow F(\beta)$, ki je definirana kot

$$
\psi_{\alpha, \beta}\left(c_{0}+c_{1} \alpha+\cdots+c_{n-1} \alpha^{n-1}\right)=c_{0}+c_{1} \beta+\cdots+c_{n-1} \beta^{n-1}
$$

za $c_{i} \in F$, je izomorfizem iz $F(\alpha)$ na $F(\beta)$ natanko tedaj, kadar sta $\alpha$ in $\beta$ konjugiranca.

Dokaz Naj bo $\psi_{\alpha, \beta}: F(\alpha) \rightarrow F(\beta)$ izomorfizem, definiran v Izreku 2.34 Naj bo $\operatorname{irr}(\alpha, F)=$ $a_{0}+a_{1} x+\cdots+a_{n} x^{n}$. Potem je $a_{0}+a_{1} \alpha+\cdots+a_{n} \alpha^{n}=0$ in je torej

$$
\psi_{\alpha, \beta}\left(a_{0}+a_{1} \alpha+\cdots+a_{n} \alpha^{n}\right)=a_{0}+a_{1} \beta+\cdots+a_{n} \beta^{n}=0
$$

Izrek 2.24 nam pove, da $\operatorname{irr}(\beta, F)$ deli $\operatorname{irr}(\alpha, F)$. Podoben argument deluje tudi za izomorfizem $\psi_{\alpha, \beta}^{-1}$, da pokažemo, da tudi $\operatorname{irr}(\alpha, F)$ deli $\operatorname{irr}(\beta, F)$. Ker pa sta oba polinoma monična, sledi, da je $\operatorname{irr}(\alpha, F)=\operatorname{irr}(\beta, F)$ in torej sledi, da sta $\alpha$ in $\beta$ konjugirana si elementa nad $F$.

Obratno, predpostavimo, da je $\operatorname{irr}(\alpha, F)=\operatorname{irr}(\beta, F)=p(x)$. Potem imata evalvacijska homomorfizma $\Psi_{\alpha}: F[x] \rightarrow F(\alpha)$ in $\Psi_{\beta}=F[x] \rightarrow F(\beta)$ enako jedro, generirano z elementom $p(x)$. Za homomorfizem $\Psi_{\alpha}: F[x] \rightarrow F(\alpha)$ obstaja naravna razširitev na izomorfizem $\psi_{\alpha}$, ki preslika $F[x] /\langle p(x)\rangle$ (kvocientni kolobar, definiran v Izreku 2.14) na $\Psi_{\alpha}[F[x]]=F(\alpha)$. Podobno tudi $\Psi_{\beta}$ poda izomorfizem $\psi_{\beta}$, ki preslika $F[x] /\langle p(x)\rangle$ na $F(\beta)$.

Naj bo sedaj $\psi_{\alpha, \beta}=\psi_{\beta}\left(\psi_{\alpha}\right)^{-1}$. Ker je preslikava $\psi_{\alpha, \beta}$ kompozicija dveh izomorfizmov, je tudi sama izomorfizem in preslika $F(\alpha)$ na $F(\beta)$. Za nek $c_{0}+c_{1} \alpha+\cdots+c_{n-1} \alpha^{n-1} \in F(\alpha)$ velja:

$$
\begin{aligned}
\psi_{\alpha, \beta}\left(c_{0}+c_{1} \alpha+\cdots+c_{n-1} \alpha^{n-1}\right) & = \\
& =\left(\psi_{\beta} \psi_{\alpha}^{-1}\right)\left(c_{0}+c_{1} \alpha+\cdots+c_{n-1} \alpha^{n-1}\right) \\
& =\psi_{\beta}\left(\left(c_{0}+c_{1} x+\cdots+c_{n-1} x^{n-1}\right)+\langle p(x)\rangle\right) \\
& =c_{0}+c_{1} \beta+\cdots+c_{n-1} \beta^{n-1} .
\end{aligned}
$$

Torej je $\psi_{\alpha, \beta}$ preslikava, definirana v Izreku 2.34

\subsection{Analitične metode}

V okviru glavnega dokaza tega magistrskega dela bodo prišle do izraza tudi nekatere metode iz analize, predvsem razvoj v potenčno vrsto in Cauchyjev integralni izrek.

DEFINICIJA 2.35 (ODVODI FUNKCIJE) Naj bo $U \subseteq \mathbb{C}$ odprta podmnožica kompleksne ravnine in naj bo $f: U \rightarrow \mathbb{C}$ kompleksna funkcija.

Za dano točko $z_{0} \in U$ rečemo, da je funkcija $f$ kompleksno odvedljiva $\mathrm{v} z=z_{0}$, če obstaja limita

$$
\lim _{z \rightarrow z_{0}} \frac{f(z)-f\left(z_{0}\right)}{z-z_{0}} .
$$


Če ta limita obstaja, ji pravimo kompleksni odvod funkcije $f \mathrm{v}$ točki $z_{0}$, ki ga označimo $\mathrm{z}$ $f^{\prime}\left(z_{0}\right)$.

DEFINICIJA 2.36 (HOLOMORFNA FUNKCIJA, CELA FUNKCIJA) Za funkcijo $f$ iz prejšnje definicije pravimo, da je holomorfna na odprti množici $U \subset \mathbb{C}$, če je kompleksno odvedljiva v vsaki točki $z_{0} \in U$. Funkcijo, ki je holomorfna na celotni kompleksni ravnini, imenujemo cela funkcija.

Zgoraj definirano holomorfno funkcijo lahko razdelimo na realni in imaginarni del, namreč: $f(z)=u(z)+i v(z)$. Če upoštevamo še $z=x+i y$, potem realni funkciji $u(z)=u(x+i y)$ in $v(z)=v(x+i y)$ zadoščata tako imenovanim Cauchy-Riemannovim enačbam:

$$
u_{x}(x+i y)=v_{y}(x+i y) \quad \text { in } \quad u_{y}(x+i y)=-v_{x}(x+i y)
$$

Privzemamo, da je bralec že seznanjen s pojmom potenčne vrste: to je neskončna vrsta ene spremenljivke oblike:

$$
f(z)=\sum_{n=0}^{\infty} a_{n}(z-a)^{n}=a_{0}+a_{1}(z-a)+a_{2}(z-a)^{2}+a_{3}(z-a)^{3}+\ldots,
$$

kjer je $a_{n}$ vodilni koeficient, $a$ konstanta, $z$ pa neodvisna spremenljivka okrog $a$. Potenčna vrsta konvergira enakomerno znotraj kroga s središčem $a$ in radijem

$$
R=\frac{1}{\limsup _{n \rightarrow \infty} \sqrt[n]{\left|a_{n}\right|}}
$$

Znotraj tega kroga tudi velja

$$
f^{\prime}(z)=\sum_{n=1}^{\infty} n a_{n}(z-a)^{n-1} .
$$

S pomočjo Cauchyjeve integralske formule, ki jo bomo zapisali v nadaljevanju, lahko pokažemo, da lahko vsako holomorfno funkcijo lokalno razvijemo v potenčno vrsto.

IZREK 2.37 (POTENČNA VRSTA FUNKCIJE) Naj bo $f: U \rightarrow \mathbb{C}$ holomorfna funkcija in $z_{0} \in \mathbb{C}$ poljubna kompleksna točka. Potem lahko funkcijo $f$ izrazimo kot potenčno vrsto okoli $z_{0}$ :

$$
f(z)=\sum_{n=0}^{\infty} \frac{f^{(n)}\left(z_{0}\right)}{n !}\left(z-z_{0}\right)^{n}
$$

Primer potenčne vrste, ki bo ključnega pomena v nadaljevanju, je vrsta za eksponentno funkcijo

$$
e^{z}=\sum_{n=0}^{\infty} \frac{z^{n}}{n !}=1+z+\frac{z^{2}}{2 !}+\frac{z^{3}}{3 !}+\ldots
$$

Na kratko si oglejmo definicijo kompleksnega integrala. Vsako kosoma gladko pot $\gamma$ : $[0,1] \rightarrow \mathbb{C}$ lahko zapišemo kot:

$$
\gamma(t)=x(t)+i y(t),
$$

kjer sta $x(t)$ in $y(t)$ kosoma zvezno odvedljivi realni funkciji na $[0,1]$. Odvod poti $\gamma$ označimo $\mathrm{z} \gamma^{\prime}$ in je

$$
\gamma^{\prime}(t)=x^{\prime}(t)+i y^{\prime}(t)
$$


Tir poti $\gamma($ slika $\gamma([0,1]))$ označimo z $\gamma *$. Če je $g:[a, b] \rightarrow \mathbb{C}$ kompleksna funkcija, definirana na realnem intervalu, definiramo:

$$
\int_{a}^{b} g(t) d t=\int_{a}^{b} \operatorname{Re}(g(t)) d t+i \int_{a}^{b} \operatorname{Im}(g(t)) d t .
$$

$\mathrm{Z}$ uporabo parametrizacije potem prevedemo na ta primer tudi integracijo kompleksnih funkcij, definiranih vzdolž tira poti.

DEFINICIJA 2.38 (KRIVULJNI INTEGRAL) Naj bosta $a<b$ realni števili. Če imamo dano kompleksno funkcijo $f: U \rightarrow \mathbb{C}$ in gladko pot $\gamma([a, b]) \subseteq U$, lahko definiramo krivuljni integral kompleksne funkcije $f$ po poti $\gamma$, ki ga označimo kot $\int_{\gamma} f(z) d z$ in je enak

$$
\int_{\gamma} f(z) d z=\int_{a}^{b} f(\gamma(t)) \gamma^{\prime}(t) d t
$$

IZREK 2.39 (CAUCHYJEV IZREK) Naj bo $f: U \rightarrow \mathbb{C}$ holomorfna funkcija in $\gamma$ enostavno sklenjena gladka pot $\mathrm{v} U$. Potem je

$$
\int_{\gamma} f(z) d z=0
$$

Dokaz Naj bo $f(z)=f(x+i y)=u(x, y)+i v(x, y)$ in $\gamma(t)=x(t)+i y(t)$. Potem je

$$
\int_{\gamma} f(z) d z=\int_{a}^{b}\left(u x^{\prime}-v y^{\prime}\right) d t+i \int_{a}^{b}\left(u y^{\prime}+v x^{\prime}\right) d t=\int_{\gamma} u d x-v d y+i \int_{\gamma} u d y-v d x .
$$

Oba integrala sta poStokesovem izreku enaka 0, saj funkciji $u$ in $v$ zadoščata Cauchy-Riemannovim enačbam.

Še več, tudi Izrek 2.39 je poseben primer naslednjega izreka.

IZREK 2.40 (CAUCHYJEVA INTEGRALNA FORMULA) Naj bo $f: U \rightarrow \mathbb{C}$ holomorfna funkcija in $\gamma$ enostavno sklenjena gladka pot $\mathrm{v} U$. Potem za poljubno celo število $n \geq 0$ in poljubno kompleksno število $z_{0}$, vsebovano $\mathrm{v}$ notranjosti območja, omejenega $\mathrm{z} \gamma$, velja:

$$
f^{(n)}\left(z_{0}\right)=\frac{n !}{2 \pi i} \int_{\gamma} \frac{f(z)}{\left(z-z_{0}\right)^{n+1}} d z
$$

Dokaz Pri $n=0$ je to natanko Cauchyjev izrek. Zdaj predpostavimo, da formula velja za $n$, in dokažimo formulo za $n+1$ :

$$
\begin{aligned}
\frac{f^{(n)}\left(z_{0}+h\right)-f^{(n)}\left(z_{0}\right)}{h} & =\frac{n !}{2 \pi i h} \int_{\gamma} f(z)\left(\frac{1}{\left(z-\left(z_{0}+h\right)\right)^{n+1}}-\frac{1}{\left(z-z_{0}\right)^{n+1}}\right) d z \\
& =\frac{n !}{2 \pi i} \int_{\gamma} f(z) \frac{\left(z-z_{0}\right)^{n}+\left(z-z_{0}\right)^{n-1}\left(z-\left(z_{0}+h\right)\right)+\cdots+\left(z-\left(z_{0}+h\right)\right)^{n}}{\left(z-\left(z_{0}+h\right)\right)^{n+1}\left(z-z_{0}\right)^{n+1}} d z \\
& \stackrel{h \rightarrow 0}{\longrightarrow} \frac{n !}{2 \pi i} \int_{\gamma} f(z) \frac{(n+1)\left(z-z_{0}\right)^{n}}{\left(z-z_{0}\right)^{2 n+2}} d z=\frac{(n+1) !}{2 \pi i} \int_{\gamma} \frac{f(z)}{\left(z-z_{0}\right)^{n+2}} d z .
\end{aligned}
$$


IZREK 2.41 (OSNOVNI IZREK ALGEBRE) Polje kompleksnih števil je algebraično zaprto.

Dokaz Naj bo $p(z)=a_{n} z^{n}+a_{n-1} z^{n-1}+\cdots+a_{0}$ nekonstanten polinom s kompleksnimi koeficienti. Potem za dovolj velike $|z|$ velja $|p(z)|>\frac{\left|a_{n}\right|}{2}|z|^{n}$, in zato $\lim _{z \rightarrow \infty} p(z)=\infty$ oziroma

$$
\lim _{z \rightarrow \infty} \frac{1}{p(z)}=0 \text {. }
$$

Če bi bil polinom $p(z)$ brez ničel, bi bila $f(x)=\frac{1}{p(z)}$ nekonstantna omejena cela funkcija. Poglejmo, da to ni mogoče.

Naj bo $|f(z)| \leq M$ za vse $z \in \mathbb{C}$. Naj bo $\gamma_{R}$ krožnica s središčem v izhodišču in radijem $R$ in naj bo $z_{0}$ poljubno kompleksno število, $\left|z_{0}\right| \leq R$. Cauchyjeva integralska formula nam pri $n=1 \mathrm{da}:$

$$
\left|f^{\prime}\left(z_{0}\right)\right|=\left|\frac{1}{2 \pi i} \int_{\gamma_{R}} \frac{f(z)}{\left(z-z_{0}\right)^{2}} d z\right| \leq \frac{M}{R} .
$$

Če pošljemo $R$ v neskončno, dobimo, da je $f^{\prime}\left(z_{0}\right)=0$. Ker je funkcija $f$ nekonstantna, to ni mogoče.

Vir analitičnih metod $\mathrm{v}$ tem delu je [10]. 


\section{Iracionalnost določenih števil}

V tem poglavju bomo dokazali, da so $n$-ti koreni, potence števila $e$ in število $\pi$ iracionalna števila. Dokazi potekajo s pomočjo protislovja in so povezani z glavnim izrekom te naloge, saj v vseh na nek način ocenjujemo zgornjo in spodnjo mejo pomožne funkcije, ki jo definiramo tekom dokaza.

Spodaj je opisan poenostavljen postopek, po katerem bodo potekali tako dokazi iracionalnosti števil kot tudi dokazi transcendentnosti.

1. Dano je število $\alpha$, za katerega želimo dokazati, da je iracionalno.

2. Predpostavimo, da je število $\alpha$ racionalno. $\mathrm{V}$ tem koraku bomo privzeli, da obstaja nek neničeln celoštevilski polinom oblike $P(x)$, tako da velja, da je $P(\alpha)=0$. Za dokazovanje iracionalnosti oziroma transcendentnosti je seveda treba izbrati primeren polinom $\mathrm{z}$ visokimi stopnjami ničel.

3. Izgradnja celega števila $N$. Uporabimo celoštevilske koeficiente prej definiranega polinoma in lastnosti števila $\alpha$, da sestavimo celo število $N$.

4. Pokažemo, da N ni enak o. Dokažemo, da je $0<|N|$. Ta korak v dokazu je običajno najtežji.

5. Iskanje zgornje meje za število $N$. Dokaz, da je $|N|<1$, ki običajno zahteva nekaj metod iz analize, za ocenjevanje maksimumov funkcij in definiranje integralov, ki nam pomagajo pri dokazovanju.

6. Osnovni princip teorije števil. Na tej točki smo pridobili celo število $0<N<1$, kar je protislovje. Če se v prejšnjih korakih nismo zmotili, je lahko edina napačna predpostavka naša osnovna predpostavka o racionalnosti števila $\alpha$.

7. Zaključek. Na tej točki lahko zaključimo, da je število $\alpha$ iracionalno.

Poleg tega zgornji postopek ne opisuje le dokazovanja iracionalnosti števil, saj na povsem analogen način poteka tudi veliko dokazov transcendentnosti števil, le da $\mathrm{v}$ ta namen $\mathrm{v}$ zgornjem postopku besedo racionalno nadomestimo $\mathrm{z}$ algebraično, besedo iracionalno pa $\mathrm{s}$ transcendentno. Med drugim bomo potrebovali naslednji izrek, ki ga navedemo brez dokaza:

IZREK 3.1 (PosplošENo LEIBNIZOVO PRAVILO) Naj bosta funkciji $f(x)$ in $g(x) n$-krat odvedljivi funkciji. Potem je tudi produkt $f g n$-krat odvedljiv in za $n$-ti odvod velja:

$$
(f g)^{(n)}=\sum_{k=0}^{n}\left(\begin{array}{l}
n \\
k
\end{array}\right) f^{(n-k)} g^{(k)} \text {. }
$$

Dokaz zgornjega izreka je na voljo v [8, s.318] 
IZREK 3.2 Število $\sqrt[n]{m}$ je iracionalno za vse $m \in \mathbb{Z}^{+}$, kjer $m$ ni $n$-ta potenca celega števila.

Dokaz Naj $m$ ne bo $n$-ta potenca celega števila in hkrati predpostavimo, da je $\sqrt[n]{m}=\frac{a}{b}$ racionalno število, kjer sta $a, b \in \mathbb{Z}, b>0$ in velja, da sta $a$ in $b$ tuji si števili. Naše število je rešitev polinoma $x^{n}-m=0$, tu pa uporabimo še našo predpostavko, da je $x=\sqrt[n]{m}$ racionalno število.

$$
\left(\frac{a}{b}\right)^{n}-m=0
$$

Iz prejšnje enačbe sledi $a^{n}=b^{n} m$. Če je $b>1$, potem mora poljuben praštevilski delitelj $p$ števila $b$ deliti tudi $a^{n}$, iz česar pa po osnovnem izreku o aritmetiki sledi, da mora $p$ deliti tudi $a$. To pa je v nasprotju s pogojem, da sta $a$ in $b$ tuji si števili, iz česar sledi, da mora biti $b=1$. Če pa je $b=1$, sledi, da je $\sqrt[n]{m}=a^{n}$, torej $n$-ta potenca števila $\mathrm{m}$, kar je v nasprotju $\mathrm{z}$ našo osnovno predpostavko. Prišli smo torej do protislovja. Sledi, da mora biti število $\sqrt[n]{m}$ iracionalno.

\subsection{Iracionalnost števila $e^{n}$}

3.2.1 $n=1$

Dokaz Glavnega pomena v dokazu iracionalnosti števila $e$ bo številska vrsta za število $e$, namreč:

$$
e=\sum_{n=0}^{\infty} \frac{1}{n !}
$$

Predpostavimo, da je $e=\frac{r}{s}$ racionalno število, kjer je $s \geq 1$. Prav s pomočjo imenovalca $s$ bomo sestavili primerno aproksimacijo za $e$, ki bo privedla do protislovja. Za ta namen si najprej ogledamo s-to delno vsoto:

$$
\sum_{n=0}^{s} \frac{1}{n !}
$$

Ker so vsi členi vsote pozitivni, sledi, da je $\frac{r}{s}-\sum_{n=0}^{S} \frac{1}{n !}>0$. Sedaj oba člena pomnožimo s s! in tako sestavimo pozitivno celo število:

$$
\begin{aligned}
s !\left(\frac{r}{s}-\sum_{n=0}^{s} \frac{1}{n !}\right)= & s !\left(e-\sum_{n=0}^{s} \frac{1}{n !}\right)=s !\left(\sum_{n=0}^{\infty} \frac{1}{n !}-\sum_{n=0}^{s} \frac{1}{n !}\right) \\
= & s !\left(\left(1+1+\frac{1}{2 !}+\cdots+\frac{1}{s !}+\frac{1}{(s+1) !}+\ldots\right)\right. \\
& \left.-\left(1+1+\frac{1}{2 !}+\cdots+\frac{1}{s !}\right)\right) \\
= & s !\left(\frac{1}{(s+1) !}+\frac{1}{(s+2) !}+\frac{1}{(s+3) !}+\ldots\right) \\
= & \frac{1}{s+1}+\frac{1}{(s+2)(s+1)}+\frac{1}{(s+3)(s+2)(s+1)}+\ldots
\end{aligned}
$$


Da je zgornje število res celo, lahko vidimo tako:

$$
s ! \frac{r}{s}-s ! \sum_{n=0}^{s} \frac{1}{n !}=(s-1) ! r-\left(\frac{s !}{1 !}+\frac{s !}{2 !}+\cdots+\frac{s !}{(s-1) !}+\frac{s !}{s !}\right) .
$$

Vsak posamezni člen zgornje vsote je celo število in je torej celotna vsota tudi celo število.

Ker pa smo postavili, da je $s \geq 1$, lahko to celo število navzgor omejimo z geometrijsko vrsto:

$$
\frac{1}{s+1}+\frac{1}{(s+2)(s+1)}+\frac{1}{(s+3)(s+2)(s+1)}+\cdots<\frac{1}{2}+\frac{1}{2^{2}}+\frac{1}{2^{3}}+\cdots=1 .
$$

Prej smo zapisali, da je $s !\left(\frac{r}{s}-\sum_{n=0}^{s} \frac{1}{n !}\right)$ celo število, kar lahko vidimo, ker je $s ! \frac{r}{s}$ celo število in hkrati tudi $s ! \sum_{n=0}^{s} \frac{1}{n !}=s !+s !+\frac{s !}{2 !}+\cdots+\frac{s !}{s !}$ celo število. Pokazali smo tudi, da je zgornje celo število enako vrsti

$$
\frac{1}{s+1}+\frac{1}{(s+2)(s+1)}+\frac{1}{(s+3)(s+2)(s+1)}+\ldots
$$

za katero pa smo pokazali, da leži med 0 in 1 . Vendar pa smo potemtakem sestavili celo število, ki leži med 0 in 1 , kar pa je v nasprotju z Izrekom 2.2 Torej mora biti $e$ iracionalno število.

Dokaza za iracionalnosti števil $e^{n}$ za $n \geq 2$ in iracionalnosti števila $\pi^{2}$ bosta povzeta po [7. s.19-20]. Oba dokaza se poslužita istega pomožnega polinoma, zato za ta namen vnaprej zapišemo ta polinom. Za dokaze definiramo pomožni polinom

$$
f(x)=\frac{x^{p}(1-x)^{p}}{p !}
$$

za $x \in[0,1]$. Poleg tega lahko bržkone ocenimo velikost naše funkcije, za katero lahko gotovo rečemo, da je na intervalu $[0,1]$ večja ali enaka 0 in hkrati manjša od $\frac{1}{p !}$, saj bosta na tem intervalu člena $x^{p}$ in $(1-x)^{p}$ gotovo manjša od 1 , torej:

$$
0 \leq f(x)<\frac{1}{p !}
$$

Zgornja funkcija je še simetrična, torej $f(x)=f(1-x)$, iz česar sledi, da bo to, kar bomo dokazali za vrednotenje $\mathrm{v}$ točki 0 , veljalo tudi za 1 .

Poleg tega bomo v okviru dokazov večkrat potrebovali različne odvode naše funkcije $f(x)$, zato jih za ta namen prav tako zapišemo:

$$
f^{\prime}(x)=\frac{p\left(x^{p-1}(1-x)^{p}-x^{p}(1-x)^{p-1}\right)}{p !} .
$$

Zapišemo še $p$-ti odvod, pomagali si bomo s posplošenim Leibnizovim pravilom iz Izreka 3.1

$$
\begin{aligned}
f^{(p)}(x)= & \sum_{k=0}^{p}\left(\begin{array}{l}
p \\
k
\end{array}\right)\left(x^{p}\right)^{(p-k)}\left((1-x)^{p}\right)^{(k)} \\
= & \left(\begin{array}{l}
p \\
0
\end{array}\right) p !(1-x)^{p}-\left(\begin{array}{c}
p \\
1
\end{array}\right) \frac{p !}{1 !} x p(1-x)^{p-1} \\
& +\left(\begin{array}{l}
p \\
2
\end{array}\right) \frac{p !}{2 !} x^{2} p(p-1)(1-x)^{p-2}-\left(\begin{array}{c}
p \\
3
\end{array}\right) \frac{p !}{3 !} x^{3} \frac{p !}{(p-3) !}(1-x)^{p-3} \\
& \vdots \\
& +\left(\begin{array}{c}
p \\
p-1
\end{array}\right) \frac{p !}{(p-1) !} x^{p-1} p !(1-x)-\left(\begin{array}{c}
p \\
p
\end{array}\right) x^{p} p !
\end{aligned}
$$


Kadar je odvod $j<p$, bo ob vrednotenju v točkah 0 in 1 rezultat funkcije (in tako odvodov) enak 0 , saj ima osnovna funkcija $f$ ničli stopnje $p \mathrm{v} 0$ in 1 . Hkrati je naš celotni polinom stopnje $2 p$, iz česar sledi, da bodo vsi naslednji odvodi, torej $j>2 p$, prav tako enaki 0 . Zapišemo tudi odvode za $p \leq j \leq 2 p$ ter jih sproti še vrednotimo v točkah 0 in 1 :

$$
\begin{gathered}
f^{(j)}(0)=p ! \frac{p !}{(2 p-j) !}(1-0)^{2 p-j}=p ! \frac{p !}{(2 p-j) !} \\
f^{(j)}(1)=(-1)^{p} p ! \frac{p !}{(2 p-j) !}(1)^{2 p-j}=(-1)^{p} p ! \frac{p !}{(2 p-j) !}
\end{gathered}
$$

Zgornje opazke lahko skrčimo v preglednejšo celoto, kjer z $A_{j}$ in $B_{j}$ označimo celi števili, odvisni od izbire $j$.

$$
\begin{aligned}
f^{(j)}(0) & = \begin{cases}p ! A_{j} & p \leq j \leq 2 p \\
0 & \text { sicer }\end{cases} \\
f^{(j)}(1) & = \begin{cases}p ! B_{j} & p \leq j \leq 2 p \\
0 & \text { sicer }\end{cases}
\end{aligned}
$$

3.2.2 $n \geq 2$

Naj bo $f(x)=\frac{x^{p}(1-x)^{p}}{p !}$ in definirajmo funkcijo $F$ :

$$
F(x)=n^{2 p} f(x)-n^{2 p-1} f^{\prime}(x)+\cdots-n f^{(2 p-1)}+f^{(2 p)}(x) .
$$

Trdimo, da sta $F(0)$ in $F(1)$ celi števili, kar sledi iz zgoraj izračunanih odvodov $f^{(j)}(0)$ in $f^{(j)}(1) \mathrm{v}(3.1)$, za katere vemo, da so cela števila, in iz dejstva, da so cela števila zaprta za seštevanje in množenje. Sedaj si oglejmo spodnji odvod:

$$
\left(e^{n x} F(x)\right)^{\prime}=n e^{n x} F(x)+e^{n x} F^{\prime}(x)=e^{n x}\left(n F(x)+F^{\prime}(x)\right) .
$$

Če si pozorno ogledamo, kako je definirana $F(x)$, lahko opazimo, da je vsota $n F(x)+F^{\prime}(x)$ enaka ravno $n^{2 p+1} f(x)$. To še zapišemo:

$$
\begin{aligned}
e^{n x}\left(n F(x)+F^{\prime}(x)\right) & =e^{n x}\left(n^{2 p+1} f(x)-n^{2 p} f^{\prime}(x)+\cdots-n^{2} f^{(2 p-1)}(x)+n f^{(2 p)}(x)\right. \\
& \left.+n^{2 p} f^{\prime}(x)-\cdots-n f^{(2 p)}(x)+f^{(2 p+1)}(x)\right) \\
& =e^{n x} n^{2 p+1} f(x) .
\end{aligned}
$$

Predpostavimo, da je $e^{n}$ racionalno število, torej $e^{n}=\frac{r}{s}$. Skupaj z ostalimi naštetimi dejstvi pa iz tega potem sledi:

$$
s \int_{0}^{1} n^{2 p+1} e^{n x} f(x) d x=\left.s\left(e^{n x} F(x)\right)\right|_{0} ^{1}=s\left(e^{n} F(1)-F(0)\right)=r F(1)-s F(0) .
$$

Za zadnji zgornji izraz lahko trdimo, da je celo število, saj so $r, s, F(0), F(1)$ cela števila. Sedaj moramo še dokazati, da je $r F(1)-s F(0)>0$. Vemo, da sta obe $r, s>0$. Zgornji integral ima tri člene, $n^{2 p-1}, e^{n x}$ in $f(x)$, pri čemer vemo, da je $n^{2 p-1}>0$, na intervalu $(0,1)$ pa sta funkciji $e^{n x}$ in $f(x)$ prav tako večji od 0 . Za $f(x)$ to lahko vidimo, če si ogledamo, kakšen predznak 
ima funkcija na odprtem intervalu $(0,1)$. Opazimo, da če v člena $x^{p}$ in $(1-x)^{p}$ vstavimo število iz intervala, je rezultat število, ki je večje od 0 . Funkcija $f(x)$ je tako na tem intervalu večja od 0 . Potemtakem pa je celoten zgornji integral večji od 0 in iz tega nemudoma sledi tudi, da je $r F(1)-s F(0)>0$.

Na začetku smo že zapisali, da je $f(x) \leq \frac{1}{p !}$, iz česar sedaj lahko ocenimo še zgornjo mejo za naš integral. Na intervalu $[0,1]$ funkcija $e^{n x}$ doseže svoj maksimum $\mathrm{v} e^{n}=\frac{r}{s}$.

$$
\left|s \int_{0}^{1} n^{2 p-1} e^{n x} f(x) d x\right| \leq \frac{s n^{2 p-1} r}{s p !}=\frac{r n^{2 p-1}}{p !}<1
$$

Za primerno izbiro števila $p$ bo zgornja meja gotovo manjša od 1.

$\mathrm{Na}$ tej točki imamo torej celo število $r F(1)-s F(0)$, za katerega velja

$$
0<r F(1)-s F(0)<1 \text {, }
$$

kar pa je protislovje. Dokaz smo s tem zaključili.

\subsection{Iracionalnost števila $\pi$ in $\pi^{2}$}

V tem delu bomo dokazali iracionalnost števila $\pi^{2}$, iz česar bo nemudoma sledila tudi iracionalnost števila $\pi$.

Predpostavimo, da je $\pi^{2}=\frac{a}{b}$ racionalno število in s pomočjo že vpeljane pomožne funkcije $f$ definiramo:

$$
F(x)=b^{p+1}\left(\pi^{2 p} f(x)-\pi^{2 p-2} f^{(2)}(x)+\ldots(-1)^{n} f^{(2 p)}(x)\right) .
$$

Oglejmo si sedaj slednji odvod:

$$
\begin{aligned}
& \left(F^{\prime}(x) \sin (\pi x)-\pi F(x) \cos (\pi x)\right)^{\prime} \\
& =F^{\prime \prime}(x) \sin (\pi x)+\pi F^{\prime}(x) \cos (\pi x)-\left(\pi F^{\prime}(x) \cos (\pi x)-\pi^{2} F(x) \sin (\pi x)\right) \\
& =F^{\prime \prime}(x) \sin (\pi x)-\pi^{2} F(x) \sin (\pi x) \\
& =\sin (\pi x)\left(F^{\prime \prime}(x)-\pi^{2} F(x)\right) .
\end{aligned}
$$

Sedaj za lažjo predstavo zapišemo še drugi odvod funckije $F(x)$ :

$$
F^{\prime \prime}(x)=b^{p+1}\left(\pi^{2 p} f^{(2)}(x)-\pi^{2 p-2} f^{(4)}(x)+\ldots(-1)^{n} f^{(2 p+2)}(x)\right) .
$$

Hkrati še zapišemo $\pi^{2} F(x)$ :

$$
\pi^{2} F(x)=b^{p+1}\left(\pi^{2 p+2} f(x)-\pi^{2 p} f^{(2)}(x)+\ldots(-1)^{n} \pi^{2} f^{(2 p+2)}(x)\right) .
$$

Opazimo lahko, da bo pri razliki $F^{\prime \prime}(x)-\pi^{2} F(x)$ večina členov izginila:

$$
\sin (\pi x)\left(F^{\prime \prime}(x)-\pi^{2} F(x)\right)=b^{p+1} \sin (\pi x)\left(\pi^{2 p+2} f(x)\right) .
$$

Sedaj uporabimo predpostavko, da je $\pi^{2}=\frac{a}{b}$ :

$$
\sin (\pi x)\left(F^{\prime \prime}(x)-\pi^{2} F(x)\right)=\sin (\pi x)\left(\pi^{2} b^{p+1}\left(\frac{a}{b}\right)^{p} f(x)\right)
$$




$$
=\sin (\pi x)\left(a^{p+1} f(x)\right) .
$$

Na tej točki si bomo ogledali integral, ki nam bo na koncu pomagal priti do protislovja, saj bomo s pomočjo tega integrala sestavili celo število, ki bo po velikosti med 0 in 1 .

$$
\begin{aligned}
\pi^{2} a^{p} \int_{0}^{1} f(x) \sin (\pi x) d x & =\left.\left(F^{\prime}(x) \sin (\pi x)-\pi F(x) \cos (\pi x)\right)\right|_{0} ^{1} \\
& =\left(F^{\prime}(1) \sin (\pi)-\pi F(1) \cos (\pi)-\left(F^{\prime}(0) \sin (0)-\pi F(0) \cos (0)\right)\right) \\
& =(\pi F(1)+\pi F(0))=\pi(F(1)+F(0))
\end{aligned}
$$

Na tej točki pokažemo, da je $F(1)+F(0)$ celo število. Ker smo predpostavili, da je $\pi^{2}=\frac{a}{b}$, bodo v funkciji $F(x)$ potence števila $\pi$ racionalna števila, po množenju s sprednjim členom $b^{p+1}$ pa cela števila. Zanimajo nas torej le še odvodi funkcije $f(x)$ vrednoteni v točkah 0 in 1. Na začetku poglavja smo že zapisali, da so vsi odvodi $f(x)$, vrednoteni v 0 ali 1 , cela števila. Iz teh dejstev potem sledi, da bosta $F(1)$ in $F(0)$ celi števili, torej enako velja tudi za $F(1)+F(0)$. Sedaj ocenimo spodnjo mejo našega integrala. Za $\pi^{2}$ in $a^{p}$ gotovo lahko rečemo, da sta pozitivni števili. Na intervalu $(0,1)$ pa sta tudi funkciji $f(x)$ in $\sin (\pi x)$ pozitivni, torej lahko trdimo:

$$
0<\pi^{2} a^{p} \int_{0}^{1} f(x) \sin (\pi x) d x=\pi(F(1)+F(0))
$$

oziroma

$$
0<F(1)+F(0) \text {. }
$$

Sedaj lahko ocenimo še zgornjo mejo integrala. Na začetku poglavja smo že povedali, da je $f(x) \leq \frac{1}{p !}$, hkrati pa je $\sin (\pi x)$ na intervalu $(0,1)$ gotovo manjši ali enak 1 , iz česar sledi:

$$
\left|\pi^{2} a^{p} \int_{0}^{1} f(x) \sin (\pi x) d x\right| \leq \frac{\pi^{2} a^{p}}{p !} .
$$

Za zadnji del zgornje neenakosti ob dovolj veliki izbiri števila $p$ velja:

$$
\frac{\pi^{2} a^{p}}{p !}<1
$$

Na tej točki smo sestavili zgornjo in spodnjo mejo za naše celo število $F(1)+F(0)$, in sicer: $0<F(1)+F(0)<1$. Tako smo prišli do protislovja, saj je to v nasprotju z izrekom 2.2

Ker smo zgoraj dokazali iracionalnost števila $\pi^{2}$, iz tega nemudoma sledi tudi iracionalnost števila $\pi$. Poraja se tudi vprašanje, kako je z iracionalnostjo števila $\pi^{n}$ za naravno število $n$, a bo na to vprašanje lažje odgovoriti, ko pokažemo še transcendentnost števila $\pi$. 


\section{Transcendentnost določenih števil}

\subsection{Transcendentnost števila e}

$\mathrm{V}$ tem poglavju predstavimo transcendentnost znanih števil $e$ in $\pi$ ter na koncu še dokaz Gelfond-Schneiderjevega izreka. Dokaz transcendentnosti števila $e$ je povzet po [2, s.4]

IZREK 4.1 Število $e$ je transcendentno.

Dokaz Predpostavimo, da je $e$ algebraično število. Naj bo $P(x)=a_{n} x^{n}+\cdots+a_{1} x+a_{0}$ minimalni celoštevilski polinom, za katerega velja $P(e)=0$. Iz pogoja minimalnosti potem sledi, da je $a_{0} \neq 0$. Definiramo integral:

$$
I(u ; f)=\int_{0}^{u} e^{u-t} f(t) d t
$$

Zgornji integral lahko integriramo s pomočjo metode per partes, kjer naj bo $u=f(t)$ in $d v=e^{u-t} d t$, iz česar sledi, da je $d v=f^{\prime}(t) d t$ in $v=-e^{e-t}$.

Iz formule za metodo per partes potem sledi:

$$
\begin{aligned}
I(u ; f) & =\left.f(t)\left(-e^{u-t}\right)\right|_{0} ^{u}+\int_{0}^{u}\left(e^{u-t} f^{\prime}(t) d t\right. \\
& =-f(u)+e^{u} f(0)+\int_{0}^{u} e^{u-t} f^{\prime}(t) d t .
\end{aligned}
$$

Zgornji proces ponavljamo, dokler ne pridemo do konca (da je proces končen, nam zagotavlja dejstvo, da je $f(x)$ polinom), iz česar nato sledi spodnja enakost:

$$
I(u ; f)=e^{u} \sum_{j \geq 0} f^{(j)}(0)-\sum_{j \geq 0} f^{(j)}(u) .
$$

Sedaj si oglejmo vsoto $a_{0} I(0 ; f)+a_{1} I(1 ; f)+\cdots+a_{n} I(n ; f)=\sum_{k=0}^{n} a_{k} I(k ; f)$. Če razpišemo posamezne člene, dobimo naslednje:

$$
\begin{gathered}
a_{0} I(0 ; f)=a_{0} e^{0} \sum_{j \geq 0} f^{(j)}(0)-a_{0} \sum_{j \geq 0} f^{(j)}(0) \\
a_{1} I(1 ; f)=a_{1} e^{1} \sum_{j \geq 0} f^{(j)}(0)-a_{1} \sum_{j \geq 0} f^{(j)}(1) \\
a_{2} I(2 ; f)=a_{2} e^{2} \sum_{j \geq 0} f^{(j)}(0)-a_{2} \sum_{j \geq 0} f^{(j)}(2) \\
\vdots \\
a_{n} I(n ; f)=a_{n} e^{n} \sum_{j \geq 0} f^{(j)}(0)-a_{n} \sum_{j \geq 0} f^{(j)}(n)
\end{gathered}
$$

Zgornje dele vsote lahko skrčimo na naslednje: 


$$
\sum_{k=0}^{n} a_{k} I(k ; f)=\sum_{j \geq 0} f^{(j)}(0)\left(a_{0} e^{0}+a_{1} e^{1}+\cdots+a_{n} e^{n}\right)-\sum_{k=0}^{n} a_{k} \sum_{j \geq 0} f^{(j)}(k) .
$$

Sedaj upoštevamo našo predpostavko, da je $e$ algebraično število, iz česar sledi:

$$
\sum_{k=0}^{n} a_{k} I(k ; f)=-\sum_{k=0}^{n} a_{k} \sum_{j \geq 0} f^{(j)}(k) .
$$

Definiramo še pomožni polinom, ki ima ničlo 0 stopnje $p-1$ in ničle $1,2,3 \ldots n$ stopnje $p$ za neko veliko praštevilo $p$ :

$$
f(x)=x^{p-1}(x-1)^{p}(x-2)^{p} \ldots(x-n)^{p} .
$$

Sedaj si bomo tako kot v prejšnjih dokazih ogledali odvode funkcije $f(x)$ za različne stopnje odvodov j. Poglejmo si najprej prvi odvod:

$$
\begin{aligned}
f^{\prime}(x) & =(p-1) x^{p-2}(x-1)^{p} \ldots(x-n)^{p} \\
& +p x^{p-1}(x-1)^{p-1} \ldots(x-n)^{p} \\
& +p x^{p-1}(x-1)^{p}(x-2)^{p-1} \ldots(x-n)^{p} \\
& \vdots \\
& +p x^{p-1}(x-1)^{p} \ldots(x-n)^{p-1} .
\end{aligned}
$$

Vidimo, da ima prvi odvod funkcije $f(x)$ ničlo $x=0$ stopnje $p-2$. Ker je v osnovni funkciji $x=0$ ničla stopnje $p-1$, bo tudi ničla vseh odvodov te funkcije, vsaj dokler ne pridemo do odvoda stopnje $p-1$. V resnici bodo prav vsi odvodi $f^{(j)}(0)=0$ za vse $j \leq p-2$. Izračunajmo še $p-1$-ti odvod v točki $x=0$ :

$$
f^{(p-1)}(0)=(p-1) !(-1)^{p}(-2)^{p} \ldots(-n)^{p} .
$$

Izračunajmo sedaj $p$-ti odvod v točki $x=0$ :

$$
\begin{aligned}
f^{(p)}(0)= & (p-1) !\left(p(-1)^{p-1}(-2)^{p} \ldots(-n)^{p}\right. \\
& +p(-1)^{p}(-2)^{p-1} \ldots(-n)^{p} \\
& \vdots \\
& \left.+p(-1)^{p}(-2)^{p} \ldots(-n)^{p-1}\right) \\
= & p !\left((-1)^{p-1}(-2)^{p} \ldots(-n)^{p}\right. \\
& +(-1)^{p}(-2)^{p-1} \ldots(-n)^{p} \\
& \vdots \\
& \left.+(-1)^{p}(-2)^{p} \ldots(-n)^{p-1}\right) .
\end{aligned}
$$

Podobno analizo odvodov lahko izvedemo tudi v vseh ostalih točkah $k=1, \ldots, n$, pri čemer seveda upoštevamo, da so $k$-ji v tem primeru ničle stopnje $p$. Oglejmo si primer za $k=1$ :

$$
f^{(p)}(1)=p ! 1^{p-1}(-1)^{p}(-2)^{p} \ldots(1-n)^{p} .
$$


Prav tako enako velja za vse ostale $k$. Da se prepričamo, zapišemo še za $k=n$ :

$$
f^{(p)}(n)=p ! n^{p-1}(n-1)^{p}(n-2)^{p} \ldots(n-(n-1))^{p} .
$$

Opaziti je mogoče, da so zgornji odvodi za vse $k$ kongruentni o modulo $p$ !, saj so preostali členi znotraj posameznega odvoda zagotovo cela števila. Vsi nadaljnji odvodi bodo za posamezen $k$ imeli mešane člene, pri katerih bo $k$ ničla in bodo tako izginili. Tako nam bodo ostali le členi, ki na koncu skupaj pripomorejo k členu $p$ !, preostanek pa bo celo število. Torej lahko trdimo, da bodo za vsak $k$ odvodi, vrednoteni $\mathrm{v} k$, kongruentni o modulo $p$ !. Sedaj lahko združimo vse informacije, ki smo jih pridobili, v naslednjo strnjeno obliko:

$$
f^{(j)}(0)= \begin{cases}0 & j \leq p-2 \\ (p-1) !(-1)^{p} \ldots(-n)^{p} & j=p-1 \\ \equiv 0 \quad(\bmod p !) & j \geq p\end{cases}
$$

Za primere $k=1,2, \ldots, n$ bo gotovo res, da bodo odvodi stopnje $j \leq p-1$ enaki 0 , saj bo funkcija imela ničlo v posameznem $k$. Iz tega torej sledi, da za vse $j \leq p-1$, razen za $j=0$, sledi $f^{(j)}(k)=0$. Prej pa smo že pokazali, da je za $j \geq p$ odvod $\mathrm{v} k$ kongruenten o modulo $p$ !. To zapišemo strnjeno:

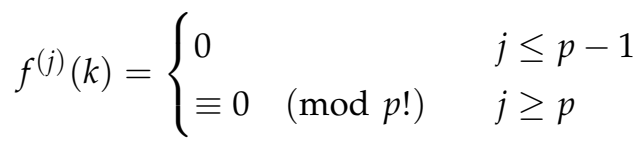

Če uporabimo vse zgornje informacije, lahko vidimo, da je $\sum_{k=0}^{n} a_{k} I(k ; f)$ celo število, saj:

$$
\begin{aligned}
\sum_{k=0}^{n} a_{k} I(k ; f)=- & \sum_{k=0}^{n} a_{k} \sum_{j=0}^{\operatorname{deg}(f)} f^{j}(k) \\
=- & \left(a_{0} \sum_{j=0}^{\operatorname{deg}(f)} f^{j}(0)+a_{1} \sum_{j=0}^{\operatorname{deg}(f)} f^{j}(1)+\cdots+a_{n} \sum_{j=0}^{\operatorname{deg}(f)} f^{j}(n)\right) \\
=- & \left(a_{0}(\overbrace{0+\cdots+0}^{(p-2)-k r a t}+(p-1) !(-1)^{p} \ldots(-n)^{p}+A_{0} p !)\right. \\
& +a_{1} \overbrace{0+\cdots+0}^{(p-1)-k r a t}+A_{j} p !) \\
& \vdots \\
& +a_{n}(\overbrace{0+\cdots+0}^{(p-1)-k r a t}+A_{n} p !) \\
= & -a_{0}(p-1) !(-1)^{p} \ldots(-n)^{p} \\
= & -a_{0}(p-1) !(-n !)^{p}+B p ! .
\end{aligned}
$$

Iz zgornje enakosti potem sledi:

$$
\left|\sum_{k=0}^{n} a_{k} I(k ; f)\right|=(p-1) !\left(\left(-a_{0}\right)(-n !)^{p}+B p\right) .
$$

Zdaj je glavna dilema, ali je lahko $\left(-a_{0}\right)(-n !)^{p}+B p=0$, iz česar bi sledilo, da je $B p=$ $(-n !)^{p} a_{0}$ oziroma da $p$ deli število $(-n !)^{p}\left(-a_{0}\right)$. Ker je $a_{0} \neq 0$, lahko vidimo, da se to ne more 
zgoditi za praštevila $p>\left|a_{0}\right| n !$.

Tako lahko rečemo, da za dovolj veliko izbiro praštevila $p$ vsota $\left(-a_{0}\right)(-n !)^{p}+B p \neq 0$. Iz zgornjih opazk potem sledi:

$$
\left|\sum_{k=0}^{n} a_{k} I(k ; f)\right| \geq(p-1) !
$$

Ocenimo lahko še zgornjo mejo na sledeč način:

Naj bo $f(x)=g^{p-1}(x) h(x)$, kjer sta $g(x)=x(x-1) \ldots(x-n)$ in $h(x)=(x-1) \ldots(x-n)$. Potem je:

$$
\max _{[0, n]}(f) \leq \max _{[0, n]}(g)^{p-1} \max _{[0, n]}(h)
$$

sedaj lahko označimo $C=\max \left\{\max _{[0, n]}(g), \max _{[0, n]}(h)\right\}$, iz česar potem sledi:

$$
\max (f) \leq C^{p} .
$$

Zapišemo lahko torej:

$$
\begin{aligned}
\left|\sum_{k=0}^{n} a_{k} I(k ; f)\right| & \leq \sum_{k=0}^{n}\left|a_{k}\right||I(k ; f)| \\
& \leq \sum_{k=0}^{n}\left|a_{k}\right| e^{n} D^{p} n ! \leq D^{p} .
\end{aligned}
$$

Tu lahko vidimo, da je $D$ neodvisen od izbire $p$. Tako smo dobili zgornjo mejo, a to pomeni:

$$
(p-1) ! \leq D^{p}
$$

kar pa gotovo ne drži za dovolj veliko izbiro praštevila $p$. Pridemo do protislovja, kar pomeni, da je bila naša osnovna predpostavka o algebraičnosti števila $e$ napačna.

\subsection{Transcendentnost števila $\pi$}

Dokaz transcendentnosti števila $\pi$ lahko poteka na več različnih načinov. V magistrskem delu se bomo osredotočili predvsem na dokaz, ki poteka s pomočjo elementarnih simetričnih polinomov, ta pa je povzet po [2, s.5]. Za ta namen naštejemo še nekaj osnovnih definicij in izrekov.

Definicija 4.2 (SIMETRIČNI POLINOM) Simetrični polinom (nad $\mathbb{Q}$ ) je polinom ali vrsta v več spremenljivkah z racionalnimi koeficienti, ki se ob permutaciji spremenljivk ne spremeni.

PRIMER 4.3 Primer simetričnega polinoma je lahko $x^{2}+y^{2}+z^{2}+2 x y z$, saj lahko hitro opazimo, da se polinom prav nič ne spremeni, če zamenjamo $x, y$ ali $z$ med seboj. Po drugi strani pa polinom $x^{2} y+y^{2} z+z^{2} x$ ni simetričen: če zamenjamo $x$ in $y$, namreč dobimo polinom $y^{2} x+x^{2} z+z^{2} y$, ki pa ni enak osnovnemu polinomu.

V okviru simetričnih polinomov poznamo tudi elementarne simetrične polinome, ki jih zapišemo za lažjo predstavo. 
- $\sigma_{1}=x_{1}+\cdots+x_{n}$

- $\sigma_{2}=x_{1} x_{2}+x_{1} x_{3}+\cdots+x_{n-1} x_{n}=\sum_{i<j} x_{i} x_{j}$

- $\sigma_{3}=\sum_{i<j<k} x_{i} x_{j} x_{k}$

- $\sigma_{n}=x_{1} x_{2} \ldots x_{n}$

Z zgornjimi polinomi lahko nato zapišemo vse simetrične polinome, kar formaliziramo v spodnjem izreku brez dokaza. Izrek bo ključen pri dokazovanju transcendentnosti števila $\pi$, saj lahko z njim zagotovimo racionalnost določenih koeficientov.

IZREK 4.4（OSNOVNI IZREK TEORIJE SIMETRIČNIH FUNKCIJ） Vsak simetrični polinom v $n$ spremenljivkah $x_{1}, \ldots, x_{n}$ ima enolično reprezentacijo z elementarnimi simetričnimi polinomi $\sigma_{1}, \ldots, \sigma_{n}$. To pomeni, da obstaja polinom $Q\left(x_{1}, \ldots, x_{n}\right)$, da velja $P\left(x_{1}, \ldots, x_{n}\right)=Q\left(\sigma_{1}, \sigma_{2}, \ldots, \sigma_{n}\right)$

Za lažjo predstavo si bomo izbrali poljubno funkcijo v treh spremenljivkah, ki jo bomo nato zapisali z osnovnimi simetričnimi funkcijami.

PRIMER 4.5 Dana je funkcija $f(x, y, z)=x^{3}+y^{3}+z^{3}$, ki jo bomo zapisali z osnovnimi simetričnimi funkcijami. Za ta namen potrebujemo naslednje osnovne simetrične funkcije:

$$
\begin{gathered}
\sigma_{1}=x+y+z \\
\sigma_{2}=x y+y z+x z \\
\sigma_{3}=x y z
\end{gathered}
$$

Če najprej kubiramo $\sigma_{1}$, dobimo: $\sigma_{1}^{3}=x^{3}+y^{3}+z^{3}+3\left(x^{2} y+y^{2} x+x^{2} z+z^{2} x+y^{2} z+z^{2} y\right)+$ $6 x y z$. Zdaj lahko zadnji člen $6 x y z$ zapišemo kot $6 \sigma_{3}$. Zapisati moramo le še sredinski člen z osnovnimi funkcijami. Če si ogledamo $3 \sigma_{1} \sigma_{2}=3(x+y+z)(x y+z y+z x)=3 x^{2} y+$ $3 x^{2} z+3 x y^{2}+3 x z^{2}+3 y^{2} z+3 z^{2} y+9 x y z$, vidimo, da smo relativno blizu želenemu produktu. Pridobili smo člen $9 x y z$, ki ga bomo odstranili, tako da bomo odšteli $9 \sigma_{3}$ za srednji člen. Z drugimi besedami torej za srednji člen velja: $3\left(x^{2} y+y^{2} x+x^{2} z+z^{2} x+y^{2} z+z^{2} y\right)=3 \sigma_{1} \sigma_{2}-$ $9 \sigma_{3}$. Zdaj lahko celotno osnovno funkcijo $f(x, y, z)$ zapišemo s $\sigma_{1}, \sigma_{2}$ in $\sigma_{3}$. Namreč:

$$
f(x, y, z)=x^{3}+y^{3}+z^{3}=\sigma_{1}^{3}-\left(3 \sigma_{1} \sigma_{2}-9 \sigma_{3}\right)-6 \sigma_{3}=\sigma_{1}^{3}-3 \sigma_{1} \sigma_{2}+3 \sigma_{3} .
$$

Poleg tega nam bosta za naslednji dokaz prišli prav tudi naslednji lemi, ki nam povesta nekaj o algebraičnih številih.

TRDITEV 4.6 Vsota in produkt dveh algebraičnih (celih) števil je algebraično (celo) število.

Za dokaz zgornje trditve, ki bo velikokrat uporabljena tudi pri dokazovanju Gelfond-Schneiderjeva izreka, potrebujemo še dodatno lemo. 
LEMA 4.7 Število $\alpha$ je algebraično število, če in samo če je $\alpha$ lastna vrednost (kvadratne) matrike nad racionalnimi števili. Hkrati je algebraično celo število, če in samo če je lastna vrednost (kvadratne) matrike nad celimi števili.

Dokaz Predpostavimo, da je $A$ kvadratna matrika nad celimi števili. Iz linearne algebre vemo, da je karakteristični polinom naše matrike $\chi_{A}(\lambda)=\operatorname{det}(\lambda I-A)$. Ker so elementi $\lambda I-A$ zgolj cela števila, sledi, da je determinanta $\chi_{A}(\lambda)$ monični polinom s celoštevilskimi koeficienti. Če je $\alpha$ lastna vrednost matrike $A$, potem je $\chi_{A}(\alpha)=0$ in je torej $\alpha$ algebraično celo število. Če je $A$ kvadratna matrika nad racionalnimi števili, lahko analogno pokažemo, da so lastne vrednosti te matrike algebraična števila.

Obratno, predpostavimo, da je $\alpha$ algebraično celo število in torej obstajajo $b_{1}, b_{2}, \ldots, b_{n} \in \mathbb{Z}$, da velja

$$
\alpha^{n}+b_{1} \alpha^{n-1}+\cdots+b_{n-1} \alpha+b_{n}=0 .
$$

Zgornji izraz lahko zapišemo kot:

$$
\alpha^{n}=-b_{1} \alpha^{n-1}-\cdots-b_{n-1} \alpha-b_{n}
$$

Naj bo sedaj v stolpični vektor

$$
\left[\begin{array}{lllll}
1 & \alpha & \alpha^{2} & \ldots & \alpha^{n-1}
\end{array}\right]^{T}
$$

tako da je:

$$
\alpha \mathbf{v}=\left[\begin{array}{c}
\alpha \\
\alpha^{2} \\
\vdots \\
\alpha^{n-1} \\
\alpha^{n}
\end{array}\right]=\left[\begin{array}{ccccc}
0 & 1 & 0 & \ldots & 0 \\
0 & 0 & 1 & \ldots & 0 \\
\vdots & \vdots & \vdots & \ddots & \vdots \\
0 & 0 & 0 & \ldots & 1 \\
-b_{n} & -b_{n-1} & -b_{n-2} & \ldots & -b_{1}
\end{array}\right]\left[\begin{array}{c}
1 \\
\alpha \\
\ldots \\
\alpha^{n-2} \\
\alpha^{n-1}
\end{array}\right]=A \mathbf{v}
$$

kjer je $A$ kvadratna matrika s celoštevilskimi elementi. Iz zgornje enakosti lahko vidimo, da je $\alpha$ res lastna vrednost matrike $A$ s pripadajočim lastnim vektorjem $\mathbf{v}$. Na podoben način lahko dokažemo, da če je $\alpha$ algebraično število, lahko najdemo kvadratno matriko $A$ nad racionalnimi števili, ki ima $\alpha$ za lastno vrednost.

Dokaz [Dokaz Trditve 4.6] Dokaz je podan za algebraična cela števila, za algebraična števila nasploh pa dokaz s primernimi popravki poteka na podoben način.

Naj bosta $\beta$ in $\gamma$ algebraični celi števili. Poiskati moramo neničelni vektor $\mathbf{w}$ in dve matriki $B$ in $C$ s celoštevilskimi elementi, da bo $B \mathbf{w}=\beta \mathbf{w}$ in hkrati $C \mathbf{w}=\gamma \mathbf{w}$. To bo impliciralo, da je $\beta+\gamma$ lastna vrednost $B+C$ in $\beta \gamma$ lastna vrednost $B C$.

Predpostavimo, da

$$
\beta^{n}+b_{1} \beta^{n-1}+\cdots+b_{n-1} \beta+b_{n}=0
$$

in

$$
\gamma^{m}+c_{1} \gamma^{m-1}+\cdots+c_{m-1} \gamma+c_{m}=0,
$$

kjer so $b_{j}$ in $c_{j}$ cela števila. Naj bo w stolpični vektor velikosti $m n$ :

$$
\left[\begin{array}{lllllllllllllll}
1 & \beta & \beta^{2} & \ldots & \beta^{n-1} & \gamma & \beta \gamma & \beta^{2} \gamma & \ldots & \beta^{n-1} \gamma & \gamma^{2} & \beta \gamma^{2} & \ldots & \beta^{n-1} \gamma^{m-1}
\end{array}\right]^{T} .
$$


Zdaj si ogledamo $\beta \mathbf{w}$. Vsi elementi tega vektorja so oblike $\beta^{j} \gamma^{k}$, kjer velja $0 \leq j<n$ in $0 \leq k<m$. Če je $j<n$, je ta element že vsebovan v w. Če pa je $j=n$, potem je:

$$
\beta^{n} \gamma^{k}=-b_{1} \beta^{n-1} \gamma^{k}-\cdots-b_{n-1} \beta \gamma^{k}-b_{n} \gamma^{k}
$$

V vsakem primeru je torej $\beta^{n} \gamma^{k}$ linearna kombinacija s celoštevilskimi koeficienti elementov vektorja w. Potemtakem obstaja celoštevilska matrika $B$, da velja $B \mathbf{w}=\beta \mathbf{w}$. Podobno obstaja tudi celoštevilska matrika $C$, da je $C \mathbf{w}=\gamma \mathbf{w}$. V splošnem sta matriki $B$ in $C$ precej grdi, a sta konstruirani na podoben način kot v dokazu prejšnje leme.

Sedaj lahko zapišemo:

$$
(B+C) \mathbf{w}=B \mathbf{w}+C \mathbf{w}=\beta \mathbf{w}+\gamma \mathbf{w}=(\beta+\gamma) \mathbf{w}
$$

in

$$
(B C) \mathbf{w}=B(C \mathbf{w})=B(\gamma \mathbf{w})=\gamma B \mathbf{w}=(\beta \gamma) \mathbf{w},
$$

kjer je $\beta+\gamma$ lastna vrednost matrike $B+C, \beta \gamma$ pa lastna vrednost matrike $B C$. Ker imata $B+C$ in $B C$ celoštevilske elemente, sta po prejšnji lemi $\beta+\gamma$ in $\beta \gamma$ algebraični celi števili.

LEMA 4.8 Če je $\alpha$ algebraično število s pripadajočim minimalnim polinomom $g(x) \in \mathbb{Z}[x]$ in je $b$ vodilni koeficient polinoma $g(x)$, potem je $b \alpha$ algebraično celo število.

Dokaz Zapišemo enačbo, ki ji zadošča $\alpha$ :

$$
b x^{n}+c_{1} x^{n-1}+\cdots+a_{n}=0 .
$$

Vidimo lahko, da če zapišemo $\beta=b \alpha$, potem lahko zapišemo pripadajočo enačbo, katere ničla je $\beta$ :

$$
x^{n}+b c_{1} x^{n-1}+b^{2} c_{2} x^{n-2}+\cdots+b^{n} c_{n}=0 .
$$

Naša nova enačba je monični polinom in sledi, da je $b \alpha \in \mathbb{Z}$.

IZREK 4.9 Število $\pi$ je transcendentno.

Dokaz Najprej lahko opazimo, da če je $\pi$ algebraično število, potem je tudi $i \pi$ algebraično število. To lahko vidimo $\mathrm{z}$ uporabo Trditve 4.6 . kjer sta $\alpha=i$ in $\beta=\pi$ algebraični števili, iz česar potem po lemi sledi, da je tudi $\alpha \beta=i \pi$ algebraično število. Zadošča torej, da pokažemo, da je število $i \pi$ transcendentno. Predpostavimo obratno, torej da je $\theta=i \pi$ algebraično število. Hkrati naj bo $r$ stopnja minimalnega polinoma $g(x)$ za $\theta$ in naj bodo $\theta_{1}=\theta, \theta_{2}, \ldots, \theta_{r}$ konjugiranci števila $\theta$. Z $b$ označimo vodilni koeficient polinoma $g(x)$. Po Lemi 4.8 potem velja, da je $b \theta_{j}$ algebraično celo število za vse $j=1, \ldots, r$.

Po Eulerjevi formuli vemo, da je $e^{i \pi}=-1$, iz česar lahko potem zapišemo:

$$
\left(1+e^{\theta_{1}}\right)\left(1+e^{\theta_{2}}\right) \ldots\left(1+e^{\theta_{r}}\right)=0 .
$$

Zgornji produkt je gotovo enak 0, saj je vsaj eden od členov enak 0. Če sedaj premnožimo zgornjo vsoto, dobimo na začetku 1 , potem pa potence števila $e$, ki imajo za eksponent le eno od $\theta_{j}$. Nato imamo potence števila $e$, ki imajo za eksponent vsoto dveh izmed $\theta_{j}$, enako za vse ostale člene, dokler na koncu ne pridemo do člena, kjer ima $e$ eksponent sestavljen iz vsote 
vseh $\theta_{j}$. Drugače lahko rečemo, da za prvi člen vsote izmed $r$ možnosti $\theta$ ne izberemo nobene, torej $\left(\begin{array}{l}r \\ 0\end{array}\right)$, za drugi člen izmed $r$ možnosti za eksponente izberemo en $\theta_{j}$, torej $\left(\begin{array}{c}r \\ 1\end{array}\right)$, za tretji člen izmed $r$ možnosti za eksponente izberemo dva $\theta_{j}$, torej $\left(\begin{array}{l}r \\ 3\end{array}\right)$. Na povsem enak način lahko utemeljimo vse eksponente števila $e$ v naši vsoti. Bralcu bo iz kombinatorike znan rezultat, da je vsota števil v $r$-ti vrstici Pascalovega trikotnika enaka ravno $2^{r}$, oziroma drugače, da je vsota binomskih simbolov $\sum_{j=0}^{r}\left(\begin{array}{l}r \\ j\end{array}\right)=2^{r}$. Iz premnožitve zgornjega produkta torej pridobimo $2^{r}$ členov, oblike $e^{\phi}$, kjer je $\phi=\epsilon_{1} \theta_{1}+\cdots+\epsilon_{r} \theta_{r}$ in je $\epsilon_{j} \in\{0,1\}$ za vse $j$. Torej lahko za primerne izbire $\epsilon_{j}$ pridobimo vse vsote, ki se pojavljajo v eksponentih števila $e$.

Sedaj s $\phi_{1}, \ldots, \phi_{n}$ označimo neničelne izmed prej definiranih izrazov. Potemtakem imamo preostalih vrednosti števil $\phi$ ravno $2^{r}-n$, ki so vsa enaka 0 , in torej lahko zapišemo:

$$
q+e^{\phi_{1}}+e^{\phi_{2}}+\cdots+e^{\phi_{n}}=0,
$$

kjer je $q=2^{r}-n$. Naj bo sedaj $p$ veliko praštevilo in hkrati

$$
f(x)=b^{n p} x^{p-1}\left(x-\phi_{1}\right)^{p} \ldots\left(x-\phi_{n}\right)^{p} .
$$

Stopnja zgornjega polinoma je $m=p(n+1)-1$, poleg tega je na začetku pomnožen $\mathrm{z} b^{n p}$, kjer $b$ izhaja iz minimalnega polinoma $g(x)$, saj s tem po Lemi 4.8 in Trditvi 4.6 zagotovimo, da bomo imeli v polinomu algebraična cela števila (eksponent je $n p$, saj imamo $n$ členov, ki je vsak stopnje $p$ ). Sedaj imamo pripravljeno orodje, da nadaljujemo dokaz.

Z uporabo Leme 4.8 in Izreka 4.4 lahko pokažemo, da ima polinom $f(x)$ celoštevilske koeficiente. To lahko lažje vidimo tako, da si ogledamo celotno množico prej definiranih $\phi$, torej $\phi_{1}, \ldots, \phi_{2^{r}}$, kjer je prvih $n$ različnih od 0 . Potem lahko zapišemo:

$$
\begin{aligned}
\left(x-\phi_{1}\right)\left(x-\phi_{2}\right) \ldots\left(x-\phi_{2^{r}}\right) & =x^{2^{r}-n}\left(x-\phi_{1}\right)\left(x-\phi_{2}\right) \ldots\left(x-\phi_{n}\right) \\
& =x^{2^{r}-n} \prod_{j=1}^{n}\left(x-\phi_{j}\right) .
\end{aligned}
$$

Ker je definiran $\phi=\epsilon_{1} \theta_{1}+\cdots+\epsilon_{r} \theta_{r}$, lahko rečemo, da je enačba (4.3) simetrična glede na $\phi$ in je torej simetrična tudi glede na $\theta_{1}, \ldots, \theta_{r}$.

Sedaj definiramo

$$
J=I\left(\phi_{1} ; f\right)+\cdots+I\left(\phi_{n} ; f\right),
$$

kjer je $I(u ; f)$ že od prej znan integral $I(u ; f)=\int_{0}^{u} e^{u-t} f(t) d t$.

Za lažje branje še enkrat zapišemo integral:

$$
I(u ; f)=e^{u} \sum_{j=0}^{\operatorname{deg}(f)} f^{(j)}(0)-\sum_{j=0}^{\operatorname{deg}(f)} f^{(j)}(u) .
$$


Sedaj lahko razpišemo prej definirano vsoto $J$ :

$$
\begin{aligned}
J= & e^{\phi_{1}} \sum_{j=0}^{m} f^{(j)}(0)-\sum_{j=0}^{m} f^{(j)}\left(\phi_{1}\right) \\
& +e^{\phi_{2}} \sum_{j=0}^{m} f^{(j)}(0)-\sum_{j=0}^{m} f^{(j)}\left(\phi_{2}\right) \\
& \vdots \\
& +e^{\phi_{n}} \sum_{j=0}^{m} f^{(j)}(0)-\sum_{j=0}^{m} f^{(j)}\left(\phi_{n}\right) \\
= & \sum_{j=0}^{m} f^{(j)}(0)\left(e^{\phi_{1}}+\cdots+e^{\phi_{n}}\right)-\sum_{j=0}^{m} \sum_{k=1}^{n} f^{(j)}\left(\phi_{k}\right) \\
= & -q \sum_{j=0}^{m} f^{(j)}(0)-\sum_{j=0}^{m} \sum_{k=1}^{n} f^{(j)}\left(\phi_{k}\right)
\end{aligned}
$$

kjer sta $m=(n+1) p-1$ in celo število $q=-e^{\phi_{1}}-\cdots-e^{\phi_{n}}$. Iz zgornje razpisane vsote lahko opazimo nekaj lastnosti. Da pokažemo, da je $J$ celo število, je dovolj, da dokažemo, da so vsi $f^{(j)}(0)$ in vse vsote $\sum_{k=1}^{n} f^{(j)}\left(\phi_{k}\right)$ simetrični polinomi v spremenljivkah $b \theta_{k}$. Ta vsota je simetrični polinom v spremenljivkah $b \phi_{k}$ in ga je torej mogoče izraziti z elementarnimi simetričnimi polinomi $\mathrm{v}$ teh istih spremenljivkah. Vsak elementarni simetrični polinom $\mathrm{v}$ spremenljivkah $b \phi_{k}$ pa je simetrični polinom v spremenljivkah $b \theta_{k}$ (po enačbi 4.3 ). Potem od tod sledi, da je to vsoto mogoče izraziti tudi z elementarnimi simetričnimi polinomi $v$ spremenljivkah $b \theta_{k}$. Simetrični polinomi v spremenljivkah $b \theta_{k}$ pa so prav racionalna cela števila. Ta polinom lahko zapišemo kot:

$$
\left(x-b \theta_{1}\right)\left(x-b \theta_{2}\right)\left(x-b \theta_{3}\right) \ldots\left(x-b \theta_{r}\right) .
$$

Zgornji polinom lahko razpišemo:

$$
\begin{aligned}
x^{r} & -x^{r-1}\left(b \theta_{1}+b \theta_{2}+\cdots+b \theta_{r}\right) \\
& +x^{r-2}\left(b^{2} \theta_{1} \theta_{2}+b^{2} \theta_{1} \theta_{3}+\cdots+b^{2} \theta_{r-1} \theta_{r}\right) \\
& -x^{r-3}\left(b^{3} \theta_{1} \theta_{2} \theta_{3}+\cdots+b^{3} \theta_{r-2} \theta_{r-1} \theta_{r}\right) \\
& \vdots \\
& (-1)^{r-1} x\left(b^{r-1} \theta_{2} \theta_{3} \ldots \theta_{r}+\cdots+b^{r-1} \theta_{1} \theta_{2} \ldots \theta_{r-1}\right. \\
& (-1)^{r}\left(b^{r} \theta_{1} \theta_{2} \ldots \theta_{r}\right)
\end{aligned}
$$

Bržkone lahko opazimo, da so koeficienti zgornjega polinoma natanko elementarni simetrični polinomi v spremenljivkah $b \theta_{k}$, ti koeficienti pa so cela števila. Poleg tega vemo, da je $f^{(j)}\left(\phi_{k}\right)=0$ za $j<p$ (polinom $f(x)$ ima namreč ničle $\mathrm{v} \phi_{1}, \ldots, \phi_{n}$ stopnje $p$ ). Na analogen način kot $\mathrm{v}$ dokazu transcendentnosti števila $e$ lahko tudi tukaj povemo nekaj o deljivosti števila $J$, v prvi vrsti, da je dvojna vsota v (4.4) celo število, deljivo s $p$ !, kar sledi iz dejstva, da je $f^{(j)}\left(\phi_{k}\right)=0$ za $j<p$.

Poleg tega je $f^{(j)}(0)=0$ za $j<p-1$ (ker ima funkcija $f$ ničlo 0 stopnje $\left.p-1\right)$ in hkrati velja, da je $f^{(j)}(0)$ deljiv s $p$ ! za $j \geq p$. Poleg tega zapišemo še $p-1$-ti odvod v točki 0 :

$$
f^{(p-1)}(0)=b^{n p}(-1)^{n p}(p-1) !\left(\phi_{1} \ldots \phi_{n}\right)^{p} .
$$


V zgornji enačbi sta $b^{n p}$ in $(-1)^{n p}$ celi števili, poleg tega pa po Izreku 4.4 vemo, da je tudi $b^{n} \phi_{1} \ldots \phi_{n}$ celo število, saj je elementarni simetrični polinom v spremenljivkah $b \theta_{k}$. Iz teh dejstev sedaj sledi, da je $f^{(p-1)}(0)$ celo število, deljivo s $(p-1)$ !. Podobno bi lahko dokazali, da za $j>p-1$ velja $f^{(j)}(0)=A_{j} p$ ! (elementarni simetrični polinom v spremenljivkah $b \theta_{k}$, kjer je $A_{j}$ celo število in je potemtakem $f^{(j)}(0)$ celo število deljivo s $p$ !).

Opazimo lahko,da za dovolj veliko praštevilo $p$ število $f^{(p-1)}(0)$ ni deljivo s $p$ in posledično $|J| \geq(p-1)$ !. Podobno kot smo v dokazu transcendentnosti števila $e$ v enačbi (4.1) ocenili zgornjo mejo, to storimo tudi zdaj:

$$
|J| \leq \sum_{k=1}^{n}\left|\phi_{k}\right| e^{\left|\phi_{k}\right|}\left|f\left(\left|\phi_{k}\right|\right)\right| \leq c_{1} c_{2}^{p}
$$

za neki konstanti $c_{1}$ in $c_{2}$, kjer $c_{1}$ predstavlja maksimum dela $\left|\phi_{k}\right| e^{\left|\phi_{k}\right|}, c_{2}$ pa maksimum funkcije $f\left(\left|\phi_{k}\right|\right)$, ki je neodvisna od izbire $p$. To lahko vidimo, če nastavimo $g(x)=x(x-$ $\left.\phi_{1}\right) \ldots\left(x-\phi_{n}\right)$ in $h(x)=\left(x-\phi_{1}\right) \ldots\left(x-\phi_{n}\right)$ in je potem $f(x)=(g(x))^{p-1} h(x)$, kjer lahko potem maksimum funkcije pridobimo na enak način kot pri dokazu transcendentnosti števila e.

Vendar pa smo tako prišli do neenakosti

$$
(p-1) ! \leq J \leq c_{1} c_{2}^{p}
$$

ki nas pripelje v protislovje pri dovolj velikem praštevilu $p$.

IZREK 4.10 Če je $x$ transcendentno število, potem je število $x^{n}$ iracionalno za vsak $n>0$.

Dokaz Predpostavimo, da je $x^{n}$ racionalno število, recimo $x^{n}=\frac{a}{b}$. Vendar pa je potem $x$ rešitev celoštevilskega polinoma $b x^{n}-a=0$ in je torej $x$ algebraično število, kar pa je protislovje.

\subsection{Gelfond-Schneiderjev izrek}

Na tej točki smo prišli do glavnega dela magistrskega dela, na katerega smo se pripravljali skozi vsa dozdajšnja poglavja. Gelfond in Schneider sta sicer Hilbertov sedmi problem rešila in dokazala neodvisno okoli leta 1934, a izrek poimenujemo po obeh. Kot zanimivost zapišemo, kako je problem leta 1900 Hilbert predstavil na Mednarodnem kongresu matematikov v Parizu.

»Hermitovi aritmetični izreki o eksponentni funkciji in Lindemannove posplošitve teh izrekov bodo gotovo požele občudovanje generacij matematikov ... Njihovo delo obravnavam kot težko, kot tudi (do sedaj še neodkrit) dokaz, da izraz $\alpha^{\beta}$ za algebraično osnovo $\alpha$ in iracionalen algebraičen eksponent $\beta$ (na primer število $2^{\sqrt{2}}$ ali pa $e^{\pi}=i^{-2 i}$ ) vedno predstavlja transcendentno ali pa vsaj iracionalno število. Gotovo je, da nas bodo rešitve teh problemov vodile do novih metod in uvidov $\mathrm{v}$ naravo posebnih iracionalnih in transcendentnih števil. $\ll 1$

\footnotetext{
${ }^{1}$ Citat je avtor prevedel sam.
} 
IZReK 4.11 Naj bo $\alpha \neq 0,1$ in $\beta$ iracionalno število. Potem $\alpha, \beta, \alpha^{\beta}$ ne morejo biti hkrati vsa algebraična števila.

Dokaz bomo povzeli po [1, s.25], v ta namen bomo potrebovali še naslednjo lemo, sicer znano kot Sieglova lema.

LEMA 4.12 (Sieglova LEMA) Naj bosta $M, N$ celi števili, kjer $N>M>0$. Za vsako celo število $j$, kjer $1 \leq j \leq N$, naj bodo $a_{i j} \quad(1 \leq i \leq M)$ cela števila $\mathrm{z}$ absolutnimi vrednostmi največ $A_{i}(\geq 1)$. Potem obstajajo cela števila $x_{1}, \ldots, x_{N}$, ki niso vsa enaka nič in $\mathrm{z}$ absolutnimi vrednostmi največ:

$$
X=\prod_{i=1}^{M}\left(N A_{i}\right)^{\frac{1}{N-M}}
$$

tako da je

$$
\sum_{j=1}^{N} a_{i j} x_{j}=0 \quad(1 \leq i \leq M)
$$

Dokaz bo potekal s pomočjo principa golobnjaka, kjer bomo sestavili nova števila $y_{1}, \ldots, y_{M}$ ter jih povezali z obstoječimi $x_{1}, \ldots, x_{N}$.

Dokaz Naj bo $B=[X]$, kjer oglati oklepaji označujejo celoštevilski del števila $X$. Obstaja $(B+1)^{N}$ množic $\left\{x_{1}, \ldots, x_{N}\right\}$ celih števil, za katere velja $0 \leq x_{j} \leq B(1 \leq j \leq N)$. Za te vrednosti $x_{j}$ velja:

$$
-V_{i} B \leq y_{i} \leq W_{i} B \quad(1 \leq i \leq M)
$$

kjer so $y_{i}=\sum_{j=1}^{N} a_{i j} x_{j}$ in je $-V_{i}$ vsota negativnih $a_{i j}, W_{i}$ pa vsota pozitivnih $a_{i j}(1 \leq j \leq N)$. Za izbran $i$ imamo za vsak $j$ natanko $N$ členov $a_{i j}$, ki imajo absolutno vrednost največ $A_{i}$. Potemtakem sledi $W_{i}+V_{i} \leq N A_{i}$. Od tod lahko sklepamo, da je število množic $\left\{y_{1}, \ldots, y_{M}\right\}$ največ

$$
\prod_{i=1}^{M}\left(N A_{i} B+1\right)
$$

kar sledi iz neenakosti $-V_{j} B<y_{j}<W_{j} B$.

Ob upoštevanju hipoteze leme, torej, da obstaja absolutna vrednost rešitev, ki je največ $X=$ $\prod_{i=1}^{M}\left(N A_{i}\right)^{\frac{1}{N-M}}$ in hkrati definiciji števila $B$, ki predstavlja celoštevilski del števila $X$ lahko potem zapišemo:

$$
\begin{aligned}
& (B+1)>\prod_{i=1}^{M}\left(N A_{i}\right)^{\frac{1}{N-M}} \\
& (B+1)^{N-M}>\prod_{i=1}^{M} N A_{i} .
\end{aligned}
$$

Iz zgornje neenakosti in hkrati po predpostavki $A_{i} \geq 1$ potem sledi:

$$
(B+1)^{N}>\prod_{i=1}^{M}\left(N A_{i} B+1\right) .
$$


Če uporabimo analogijo golobnjaka, imamo torej dve množici (goloba) izmed $\left\{x_{1}, \ldots, x_{N}\right\}, \mathrm{ki}$ pripadata isti množici (golobnjaku) izmed $\left\{y_{1}, \ldots, y_{M}\right\}$. Rešitev našega problema je razlika teh dveh množic, ki pripadata isti množici izmed $\left\{y_{1}, \ldots, y_{M}\right\}$.

Dokaz [Dokaz Izreka 4.11] Predpostavimo, da so $\alpha, \beta, \alpha^{\beta}$ algebraična števila. Naj bo $F$ polje števil $\mathbb{Q}\left(\alpha, \beta, \alpha^{\beta}\right)$ in predpostavimo, da ima stopnjo $d$. S $h, k$ označimo pozitivni števili, s $c_{1}, c_{2}, \ldots$ pozitivna števila, neodvisna od izbire $h, k$, in z $D_{1}, D_{2}, \ldots$ pozitivna števila, neodvisna od $k$, a morda odvisna od $h$. S pomočjo metode pomožnih funkcij sestavimo spodnjo funkcijo:

$$
\phi(z)=\sum_{\lambda=0}^{L} \sum_{\mu=0}^{L} p(\lambda, \mu) \alpha^{(\lambda+\mu \beta) z},
$$

kjer naj bo $L=[\sqrt{2 d h k}]$ (oglati oklepaji ponovno predstavljajo celoštevilski del) in so $p(\lambda, \mu)$ cela števila, ne vsa enaka nič, tako da velja:

$$
\phi^{(j)}(l)=0 \quad(1 \leq l \leq h, \quad 0 \leq j<k),
$$

kjer $\phi^{(j)}$ označuje $j$-ti odvod funkcije $\phi$ po $z$. Če zgornjo funkcijo odvajamo enkrat, dobimo:

$$
\begin{aligned}
\phi^{\prime}(l) & =\sum_{\lambda=0}^{L} \sum_{\mu=0}^{L} p(\lambda, \mu)(\lambda+\mu \beta) \alpha^{(\lambda+\mu \beta) l}(\log \alpha) \\
& =(\log \alpha) \sum_{\lambda=0}^{L} \sum_{\mu=0}^{L} p(\lambda, \mu)(\lambda+\mu \beta) \alpha^{(\lambda+\mu \beta) l} .
\end{aligned}
$$

Hitro lahko opazimo, da odvodi ne bodo preveč problematični, zato zapišemo:

$$
\phi^{(j)}(l)=(\log \alpha)^{j} \sum_{\lambda=0}^{L} \sum_{\mu=0}^{L} p(\lambda, \mu)(\lambda+\mu \beta)^{j} \alpha^{(\lambda+\mu \beta) l} .
$$

Sedaj lahko pogledamo, koliko enačb imamo v zgornji enakosti. Ogledamo si člene, kjer nastopata $\alpha$ in $\beta$, in opazimo, da je $j$ navzgor omejen $\mathrm{s} k, l$ pa navzgor omejen $\mathrm{s} h$, zato lahko zapišemo, da imamo $M^{\prime}=h k$ linearnih enačb v neznankah $p(\lambda, \mu)$, katerih pa je, če si ogledamo vsote in opazimo, da $\lambda$ in $\mu$ tečeta od 0 do $L$, natanko $N=(L+1)^{2}$.

Vemo, da če je $\gamma$ algebraično število, potem po Lemi 4.8 obstaja tako celo število $A$, da je $A \gamma$ algebraično celo število (torej rešitev moničnega polinoma). Zdaj bomo vsak posamezni člen, ki vsebuje $\alpha, \beta$ ali $\alpha^{\beta}$, pomnožili s primernim $A$-jem, tako da bodo vsa števila, ki nastopajo v vsoti (4.6), postala algebraična cela števila. Na tej točki večkrat uporabimo Lemo 4.6 in Lemo 4.8. saj sestavljamo algebraična cela števila in hkrati jemljemo vsoto in produkte algebraičnih števil. Prvi člen, ki vsebuje $\beta$, je $(\lambda+\mu \beta)^{j}$, ki ima stopnjo $j$, zato mu od $k$ možnih $A$-jev primnožimo $j$ (tu uporabimo Lemo 4.8):

$$
(A \lambda+A \mu \beta)^{j} A^{k-j} .
$$

Člen $\alpha^{(\lambda+\mu \beta) l}$ razbijemo na dva dela, na $\alpha^{\lambda l}$ in $\alpha^{\mu \beta l}$. Na tej točki sedaj uporabimo obe Lemi, 4.6 in 4.8 Prvi izmed dveh delov $\alpha$ ima eksponent $\lambda l$. Za tega imamo na voljo $L h$ potenc $A-j a$ ( $L$ je maksimum $\lambda, h$ pa je maksimum $l$ ):

$$
(A \alpha)^{\lambda l} A^{L h-\lambda l} .
$$


Enako naredimo še za zadnji člen $a^{\mu \beta l}$, kjer spet upoštevamo, da je $L$ maksimum $\mu, h$ pa maksimum $l$ ter ponovno uporabimo Lemo 4.6

$$
\left((A \alpha)^{\beta}\right)^{\mu l} A^{L h-\mu l} .
$$

Če nato posamezne $A$ - je zmožimo, na koncu dobimo potrebno potenco $A-j a$, tako da bodo koeficienti enačb (4.6) algebraična cela števila:

$$
A^{j} A^{k-j} A^{\lambda l} A^{L h-\lambda l} A^{\mu l} A^{L h-\mu l}=A^{2 L h+k} .
$$

Tako smo odkrili, da moramo celotne enačbe (4.6) pomnožiti z $A^{2 L h+k}$.

Zdaj lahko ocenimo še velikosti koeficientov enačb (4.6). Tako kot prej sta $\lambda$ in $\mu$ omejena z $L, j$ je omejen $\mathrm{s} k, l$ pa je omejen $\mathrm{s} h$. Te omejitve sedaj vstavimo $\mathrm{v}$ našo oceno velikosti teh koeficientov:

$$
(\lambda+\mu \beta)^{j} \alpha^{(\lambda+\mu \beta) l}=(L+L \beta)^{k} \alpha^{(L+L \beta) h} .
$$

Zdaj le še nastavimo, da je $c_{1}=1+\beta$ ter $c_{2}=\alpha^{1+\beta}$; lahko rečemo, da imajo koeficienti naših enačb velikost največ:

$$
\left(c_{1} L\right)^{k} c_{2}^{L h}
$$

Naš j-ti odvod je po množenju s primernim $A$-jem oblike:

$$
A^{2 L h+k} \phi^{(j)}(l)=\log (\alpha)^{j} \sum_{\lambda=0}^{L} \sum_{\mu=0}^{L} p(\lambda, \mu) a_{\lambda, \mu, j, l},
$$

kjer $a_{\lambda, \mu, j, l}=(A \lambda+\mu \beta A)^{j} A^{k-j}(\alpha A)^{\lambda l} A^{L h-\lambda l}\left(\alpha^{\beta} A\right)^{\mu l} A^{L h-\mu l}$. Za ta $a_{\lambda, \mu l, j, l}$ lahko zaradi Lem 4.6 in 4.8 trdimo, da so algebraična cela števila, vsebovana v polju $F$ stopnje $d$, in predstavljajo koeficiente naše enačbe. Iz tega sledi, da obstaja baza algebraičnih števil $w_{1}, \ldots, w_{d}$ polja $F$, kar pomeni, da lahko vsak prej zapisani $a_{\lambda, u, j, l}$ zapišemo kot celoštevilsko linearno kombinacijo števil $w_{1}, \ldots, w_{d}$, torej $a_{\lambda, \mu, j, l}=c_{\lambda, \mu, j, l}^{1} w_{1}+\cdots+c_{\lambda, \mu, j, l}^{d} w_{d}$, kjer so $c_{\lambda, \mu, j, l}^{j}$ cela števila. Na tej točki lahko prejšnjo enačbo odvoda zapišemo drugače:

$$
A^{2 L h+k} \phi^{(j)}(l)=\log (\alpha)^{j} \sum_{t=1}^{d} w_{t} \sum_{\lambda=0}^{L} \sum_{\mu=0}^{L} p(\lambda, \mu) c_{\lambda, \mu, j, l}^{t} .
$$

Na začetku smo imeli $M^{\prime}=h k$ enačb v neznankah $p(\lambda, \mu)$, ker pa smo zdaj koeficiente $a_{\lambda, \mu}$ izrazili s pomočjo baze $w_{1}, \ldots, w_{d}$, pridobimo $M=d M^{\prime}=d h k$ linearnih enačb s celoštevilskimi koeficienti. Ti koeficienti imajo absolutno vrednost največ $\left(c_{3} L\right)^{k} c_{2}^{L h}$

S pomočjo Sieglove leme lahko sedaj ocenimo velikost naših neznank $p(\lambda, \mu)$. Velja $N \geq c_{4} L^{2}$ in hkrati $\frac{M}{N-M} \leq 1$. Če upoštevamo, da je $N=(L+1)^{2}=2 d h k+2 \sqrt{2 d h k}+1>2 d h k$, sledi:

$$
\frac{M}{N-M}<\frac{d h k}{2 d h k-d h k}=1 \text {. }
$$

Če zdaj sestavimo oceno z lemo, pri čemer bomo namesto $A_{i}$ zapisali $\left(c_{3} L\right)^{k} c_{2}^{L h}$, dobimo:

$$
\left(N\left(c_{3} L\right)^{k} c_{2}^{L h}\right)^{\frac{M}{N-M}} .
$$

Zdaj naredimo nekaj poenostavitev, in sicer:

Naj bo $\left(c_{3} L\right)^{k} \sim\left(c_{3} \sqrt{2 d h k}\right)^{k}$ in hkrati iz $N \geq c_{4} L^{2}$ sledi $L \leq \sqrt{\frac{N}{c_{4}}}$ in torej $c_{2}^{L h} \leq c_{2}^{\sqrt{\frac{N h^{2}}{c_{4}}}}$. Potem 
lahko zapišemo:

$$
\begin{aligned}
\left(N\left(c_{3} L\right)^{k} c_{2}^{L h}\right)^{\frac{M}{N-M}} & \leq\left(2 d h k\left(c_{3} \sqrt{2 d h k}\right)^{k} c_{2}^{\sqrt{\frac{N h^{2}}{c_{4}}}}\right) \\
& =\left((2 d h k)^{1+\frac{k}{2}} c_{3}^{k} c_{2}^{\sqrt{\frac{2 d k h^{3}}{c_{4}}}}\right) \\
& \leq\left((2 d h k)^{k} c_{3}^{k} c_{2}^{k \cdot \sqrt{\frac{2 d h^{3}}{c_{4}}}}\right)
\end{aligned}
$$

Naj bo sedaj $D_{1}=2 d h c_{3} \cdot c_{2}^{\sqrt{\frac{2 d h^{3}}{c_{4}}}}$, iz česar potem sledi

$$
\left(\left(2 d h c_{3} c_{2}^{\sqrt{\frac{2 d h^{3}}{c_{4}}}}\right)^{k} k^{k}\right)=\left(D_{1} k\right)^{k}
$$

iz česar sledi, da lahko cela števila $p(\lambda, \mu)$ izberemo tako, da imajo absolutne vrednosti največ $\left(D_{1} k\right)^{k}$.

Vemo, da za $K=k$ velja (naša indukcijska predpostavka):

$$
\phi^{(j)}(l)=0 \quad(1 \leq l \leq h, \quad 0 \leq j<K) .
$$

$V$ indukcijskem koraku sedaj predpostavimo, da to velja za nek $K \geq 1$ in dokažimo, da velja tudi za $K+1$.

Sedaj definiramo polinom:

$$
F(z)=(z-1) \ldots(z-h)
$$

in hkrati definiramo funkcijo $\frac{\phi(z)}{F(z)^{K}}$, ki je cela, saj ima po predpostavki funkcija $\phi$ ničle reda vsaj $K \mathrm{v}$ točkah $1, \ldots, l$. Potemtakem lahko uporabimo Cauchyjevo integralno formulo:

$$
\frac{K !}{2 \pi i} \int_{\gamma} \frac{\phi(z)}{F(z)^{K}(z-l)} d z=\left[\frac{d^{K}}{d z^{K}}\left(\frac{\phi(z)(z-l)^{K}}{(F(z))^{K}}\right)\right]_{z=l}=\frac{\phi^{(K)}(l)}{\left(F^{\prime}(l)\right)^{K}}
$$

kjer je $\gamma$ pozitivno orientirana krožnica s središčem v koordinatnem izhodišču in radijem $R=\sqrt{K}$, tako da $R$ presega $2 h$, kadar se $k$ približuje neskončnosti (s tem zagotovimo, da so vse ničle naše funkcije znotraj naše definirane krožnice). Do zadnjega dela enakosti v enačbi (4.7) pridemo z večkratno uporabo L'Hôpitalovega pravila. Funkcija $\frac{\phi(z)}{F(z)^{K}}$ ima v $1,2, \ldots, h$ odpravljive singularnosti, zato jo lahko razširimo do cele funkcije $g(z)=\frac{K !}{2 \pi i} \int_{\gamma} \frac{g(z)}{(z-l)} d z=$ $K ! g(l)=K ! \lim _{z \rightarrow l} \frac{\phi(z)}{F(z)^{K}}$. Na tej točki za izračun naše limite uporabimo L'Hôpitalovo pravilo: 


$$
\begin{aligned}
& K ! \lim _{z \rightarrow l} \frac{\phi(z)}{F(z)^{K}} \stackrel{L^{\prime} H}{=} K ! \lim _{z \rightarrow l} \frac{\phi^{\prime}(z)}{K F^{K-1}(z) F^{\prime}(z)} \\
&=\frac{K !}{F^{\prime}(l) K} \lim _{z \rightarrow l} \frac{\phi^{\prime}(z)}{F^{K-1}(z)} \\
& \stackrel{L^{\prime} H}{=} \frac{K !}{F^{\prime}(l) K} \lim _{z \rightarrow l} \frac{\phi^{\prime \prime}(z)}{(K-1) F^{K-2}(z) F^{\prime}(z)} \\
&=\frac{K !}{K(K-1)\left(F^{\prime}(l)\right)^{2}} \lim _{z \rightarrow l} \frac{\phi^{\prime \prime}(z)}{F^{K-2}(z)} \\
& \vdots \\
&=\frac{K ! \phi^{(K)}(l)}{K !\left(F^{\prime}(l)\right)^{K}}=\frac{\phi^{(K)}(l)}{\left(F^{\prime}(l)\right)^{K}} .
\end{aligned}
$$

Za $z$ na $\gamma$ si lahko pomagamo še s prejšnjo oceno za cela števila $p(\lambda, \mu)$ in hkrati $k$ nadomestimo $\mathrm{z}$ velikim $K$ ter označimo $c_{5}=\alpha^{(1+\beta)}$ in upoštevamo, da je $R$ maksimum $z$ :

$$
|\phi(z)| \leq \sum_{\lambda=0}^{L} \sum_{\mu=0}^{L}|p(\lambda, \mu)| \cdot\left|\alpha^{(\lambda+\mu \beta) z}\right| \leq\left(D_{2} K\right)^{K} \cdot c_{5}^{L R} .
$$

Sedaj upoštevamo še, da je $R=\sqrt{K}$ :

$$
\left(D_{2} K\right)^{K} c_{5}^{L \sqrt{K}} \leq\left(D_{2} K\right)^{K}\left(c_{5}^{L}\right)^{K}=\left(D_{3} K\right)^{K},
$$

kjer je $D_{3}=D_{2} c_{5}^{L}$.

Sedaj lahko ocenimo velikost leve strani enačbe 4.7.

$$
\left|\frac{K !}{2 \pi i} \int_{\gamma} \frac{\phi(z)}{F(z)^{K}(z-l)} d z\right| \leq \frac{K !}{2 \pi i} \int_{\gamma} \frac{|\phi(z)|}{|F(z)|^{K}|(z-l)|} d z .
$$

Nastavimo $|F(z)| \geq\left(\frac{R}{2}\right)^{h}$ (potenca je $h$, saj ima funkcija $F(z) h$ členov) in velja $|z-l| \geq \frac{R}{2}$ za $z \in \gamma$ (krožnica $z$ radijem $R$, ki je neodvisen od $h$ ). Potem je:

$$
\begin{aligned}
\frac{K !}{2 \pi i} \int_{\gamma} \frac{|\phi(z)|}{|F(z)|^{K}|(z-l)|} d z & \leq \frac{K !}{2 \pi i} \frac{\left(D_{3} K\right)^{K}}{\left(\frac{R^{h}}{2}\right)^{K} \frac{R}{2}}=\frac{K !}{2 \pi i} \frac{\left(D_{3} K\right)^{K}}{\left(\frac{R}{2}\right)^{h K+1}} \\
& =\frac{K !}{2 \pi i} \frac{\left(D_{3} K\right)^{K}}{\left(\frac{1}{2}\right)^{h K+1}(\sqrt{K})^{h K+1}} \leq K ! \frac{\left(D_{4} K\right)^{K}}{K^{\frac{h K+1}{2}}} \\
& =K ! D_{4}^{K} K^{K\left(1-\frac{h}{2}\right)} .
\end{aligned}
$$

Pokazali smo torej, da je leva stran enačbe 4.7

$$
\left|\frac{K !}{2 \pi i} \int_{\gamma} \frac{\phi(z)}{F(z)^{K}(z-l)} d z\right| \leq K ! D_{4}^{K} K^{K\left(1-\frac{h}{2}\right)} .
$$

Da ocenimo še desno stran enačbe, najprej opazimo, da je $(\log \alpha)^{-K} \phi^{(K)}(l)$ algebraično število (namreč, $(\lambda+\mu \beta)$ in $\alpha^{(\lambda+\mu \beta)}$ sta obe algebraični, prav tako $p(\lambda, \mu)$ ). Tako kot prej lahko ta števila pomnožimo s primernim številom, da pridobimo algebraično celo število, za ta namen pa se spet poslužimo Lem 4.6 in 4.8 . Torej:

$$
(A \lambda+A \mu \beta) A^{K-k},
$$




$$
(A \alpha)^{L l-\lambda l}\left((A \alpha)^{\beta}\right) A^{L l-\mu l} .
$$

Če zdaj vse te primerne $A$-je zmnožimo med seboj:

$$
A^{k} A^{K-k} A^{\lambda l} A^{L l-\lambda l} A^{\mu l} A^{L l-\mu l}=A^{K+2 L l} .
$$

Če celotno enačbo pomnožimo z $A^{K+2 L l}$, pridobimo algebraično celo število, ki ga ocenimo na podoben način kot prej. Poznamo $p(\lambda, \mu) \leq\left(D_{1} K\right)^{K}$ in hkrati $(\lambda+\mu \beta)^{K} \leq\left(L c_{1}\right)^{K}$ ter $\alpha^{(\lambda+\mu \beta) l} \leq c_{2}^{L h}$. Poleg tega izberemo $k$, ki je dovolj velik, da bo $\sqrt{k}>2 h$, iz česar sledi, da je $k>2 h$. Zdaj ocene zmožimo:

$$
\left(D_{1} K\right)^{K}\left(L c_{1}\right)^{K} c_{2}^{L h} \leq\left(D_{1} K\right)^{K}\left(L c_{1}\right)^{K} c_{2}^{L K}=K^{K}\left(D_{1} L c_{1} c_{2}^{L}\right)^{K}=\left(D_{5} K\right)^{K}
$$

Pokazali smo torej, da ima algebraično celo število $A^{2 L l+K}(\log \alpha)^{-K} \phi^{(K)}(l)$ velikost največ $\left(D_{5} K\right)^{K}$. Ko govorimo o oceni velikosti algebraičnega števila, imamo v mislih maksimalno vrednost tega števila in njegovih konjugirancev.

Da lahko ocenimo velikost algebraičnega števila in njegovih konjugirancev, potrebujemo še dodatno lemo, ki jo navajamo tu:

LEMA 4.13 Naj bo $\alpha$ algebraično število nad $Q$ in naj $N(\alpha)$ označuje produkt $\alpha$ in vseh njegovih konjugirancev. Če je $\alpha$ algebraično celo število, potem je $N(\alpha)$ nujno celo število, različno od 0 . Če z $\alpha=\alpha_{1}, \ldots, \alpha_{n}$ označimo konjugirance števila $\alpha$, potem velja $\left|\alpha_{1}\right| \geq\left|\alpha_{2} \ldots \alpha_{n}\right|^{-1}$.

Dejstvo, da je $N(\alpha)$ celo število, če je $\alpha$ algebraično celo število, sledi direktno iz dejstva, da imamo minimalni polinom $f(x)$ (ki ima celoštevilske koeficiente), ki mu pripadajo $\alpha$ in vsi njegovi konjugiranci. Potemtakem lahko zapišemo:

$$
f(x)=x^{n}+a_{n-1} x^{n-1}+\cdots+a_{0}=\left(x-\alpha_{1}\right)\left(x-\alpha_{2}\right) \cdots\left(x-\alpha_{n}\right)=x^{n}+\cdots+\alpha_{1} \alpha_{2} \ldots \alpha_{n}
$$

kjer je zadnji člen nujno različen od 0 , saj bi lahko sicer imeli polinom nižje stopnje, kot je bil prvotni minimalni polinom. Iz zgornjega zapisa potemtakem tudi sledi, da je $N(\alpha)=$ $\alpha_{1} \ldots \alpha_{n}=(-1)^{n} a_{0}$ in mora torej biti res $N(\alpha) \in \mathbb{Z}$, kadar je $\alpha$ algebraično celo število. Celotni dokaz prejšnje leme lahko bralec najde v [9. Lema 7.1]. Prej smo že izračunali, da je velikost našega algebraičnega celega števila največ $\left(D_{5} K\right)^{K}$. To seveda velja za število $\alpha$ in tudi vse njegove konjugirance, saj bi lahko izračun za velikost vsakega konjugiranca izpeljali na enak način, kot je bil izpeljan za $\alpha$. Enaka ocena torej velja tudi za vse njegove konjugirance, zato iz Leme 4.13 sledi:

$$
\left|A^{2 L l+K}(\log \alpha)^{-K} \phi^{(K)}(l)\right| \geq\left(D_{5} K\right)^{-n K} .
$$

Ker pa naše algebraično celo število pripada polju $F$ stopnje $d$ nad $\mathbb{Q}$, sledi, da ima to število največ $d-1$ konjugirancev, torej velja $n<d$, zato lahko zapišemo:

$$
\left|A^{2 L l+K}(\log \alpha)^{-K} \phi^{(K)}(l)\right| \geq\left(D_{5} K\right)^{-d K},
$$

iz česar potem nemudoma sledi

$$
\left|\phi^{(K)}(l)\right|>\log (\alpha)^{K} A^{-(2 L l+K)}\left(D_{5} K\right)^{-d K}=\left(D_{6} K\right)^{-d K} .
$$

Predpostavimo še, da je $h>2(d+2)$. Izračunamo prvi odvod funkcije $F(z)$ in ga vrednotimo $\mathrm{v}$ točki $l$. Večina členov tega odvoda bo enaka 0 . Ostal bo zgolj en in člen - natanko tisti, kjer je 
odvajani člen $(z-l)$, saj ob vrednotenju $\mathrm{v} l$ ta ne bo enak 0 :

$$
F^{\prime}(l)=(l-1)(l-2) \ldots(l-l-1)(l-l+1) \ldots(l-h) .
$$

Zgornji odvod bi lahko premnožili, a to ni potrebno, da opazimo, da je odvod celo število in hkrati odvisno zgolj od izbire $h$. Torej lahko zapišemo, da je $\left|F^{\prime}(l)\right| \leq D_{7}$.

$\mathrm{Na}$ tej točki lahko zapišemo zgornjo in spodnjo mejo za enačbo 4.7 , za preglednost to enačbo označimo $z \mathcal{I}$.

$$
\begin{aligned}
\left(D_{8} K\right)^{-d K}<\mathcal{I} & <K ! D_{4}^{K} K^{K\left(1-\frac{h}{2}\right)} \\
\left(D_{8} K\right)^{-d K} & <K ! D_{4}^{K} K^{K\left(1-\frac{h}{2}\right)}
\end{aligned}
$$

Če zdaj predpostavimo, da je $h=2(d+3)$, lahko zapišemo:

$$
\begin{aligned}
\left(D_{8} K\right)^{-d K} & <K ! D_{4}^{K} K^{K(1-(d+3))} \\
\left(D_{8} K\right)^{-d K} & <K ! D_{4}^{K} K^{-(d K+2 K)} \\
\frac{K^{d K} K^{2 K}}{D_{8}^{d K} K^{d K}} & <K ! D_{4}^{K} \\
K^{2 K} & <K ! D_{4}^{K} D_{8} .
\end{aligned}
$$

Zadnja neenakost je gotovo protislovje za $k$ in posledično za dovolj velik $K$. Potemtakem je $\phi^{(K)}(l)=0$ za $1 \leq l \leq h$.

Sedaj z indukcijo še pokažemo, da je $\phi^{(k)}(l)=0(1 \leq l \leq h)$ za vse $k$. Ker je $\phi(z)$ cela funkcija, to implicira po Izreku 2.37 da je $\phi(z)$ identično enaka 0 . Natančneje:

$$
\phi^{(j)}(0)=0 \quad\left(1 \leq j \leq(L+1)^{2}\right),
$$

kar je enako kot:

$$
\sum_{\lambda=0}^{L} \sum_{\mu=0}^{L} p(\lambda, \mu)(\lambda+\mu \beta)^{j}=0 \quad\left(1 \leq j \leq(L+1)^{2}\right) .
$$

Zgornje člene $(\lambda+\mu \beta)^{j}$ lahko zložimo v matriko

$$
V=\left[\begin{array}{ccccc}
1 & x_{1} & x_{1}^{2} & \ldots & x_{1}^{L} \\
1 & x_{2} & x_{2}^{2} & \ldots & x_{2}^{L} \\
1 & x_{3} & x_{3}^{2} & \ldots & x_{3}^{L} \\
\vdots & \vdots & \vdots & \ldots & \vdots \\
1 & x_{L} & x_{L}^{2} & \ldots & x_{L}^{L}
\end{array}\right]
$$

reda $(L+1)^{2}$. Iz zgornjih enačb sledi, da so vrstice te matrike linearno odvisne, torej je determinanta te matrike enaka 0 . To pa je ravno Vandermondova determinanta, za katero vemo, da je enaka 0 , če in samo če velja $x_{i}=x_{j}$ za neka $i \neq j$. Označimo z $x_{i}=\left(\lambda_{i}+\mu_{i} \beta\right)$. Ker pa imamo Vandermondovo determinanto, ki je enaka 0 , to pomeni, da sta dva elementa znotraj enaka, na primer:

$$
\lambda_{i}+\mu_{i} \beta=\lambda_{j}+\mu_{j} \beta
$$

Iz tega potem sledi, da je:

$$
\beta=\frac{\lambda_{j}-\lambda_{i}}{\mu_{i}-\mu_{j}}
$$

torej, da je $\beta$ racionalno število, kar pa je v nasprotju s hipotezo našega izreka, da je $\beta$ iracionalno število. Dokaz izreka je s tem končan. 


\subsubsection{Primer uporabe Gelfond-Schneiderjevega izreka}

Zgornji izrek je izjemno močno orodje za dokazovanje transcendentnosti števil oblike $\alpha^{\beta}$, pri čemer $\alpha \neq 0,1$ in $\beta$ iracionalno število. Spodaj je naštetih le nekaj najbolj znanih števil, katerih transcendentnost lahko dokažemo s pomočjo Gelfond-Schneiderjevega izreka.

- Če je $\alpha=2$ in $\beta=\sqrt{2}$, so hipoteze izreka izpolnjene in nemudoma sledi, da je $2^{\sqrt{2}}$ transcendentno število. To število poimenujemo tudi Gelfond-Schneiderjeva konstanta, čeprav je njegovo transcendentnost pokazal Rodion Kuzmin leta 1930, Gelfond in Schneider pa sta kasneje neodvisno rezultat tudi posplošila.

- Kvadratni koren Gelfond-Schneiderjeve konstante je prav tako transcendentno število, saj lahko zapišemo $\sqrt{2^{\sqrt{2}}}=\sqrt{2}^{\sqrt{2}}$ in so torej za $\alpha=\beta=\sqrt{2}$ hipoteze izreka zadoščene in takoj sledi transcendentnost tega števila. Še več, prav s to konstanto lahko pokažemo še, da je mogoče, da se zgodi, da je iracionalno število na potenco iracionalnega števila racionalno število. Potek dokaza je približno tak:

- Če je $\sqrt{2}^{\sqrt{2}}$ iracionalno (kar v resnici je; to lahko vidimo, če uporabimo GelfondSchneiderjev izrek za $\alpha=\sqrt{2}$ in $\beta=\sqrt{2}$ ), potem lahko zapišemo:

$$
\left(\sqrt{2}^{\sqrt{2}}\right)^{\sqrt{2}}=\sqrt{2}^{\sqrt{2} \sqrt{2}}=\sqrt{2}^{2}=2
$$

- Če je $\alpha=i$ in $\beta=-2 i$, takoj sledi, da je $i^{-2 i}$ transcendentno število. Če upoštevamo, da je $i=e^{i \frac{\pi}{2}}$, po Eulerjevi enačbi sledi, da je $i^{-2 i}=\left(e^{i \frac{\pi}{2}}\right)^{-2 i}=e^{\pi}$ in torej sledi, da je število $e^{\pi}$ transcendentno.

- Če je $\alpha=i$ in $\beta=i$, so hipoteze izreka prav tako izpolnjene in sledi, da je $\alpha^{\beta}=i^{i}$ transcendentno število. Če upoštevamo še Eulerjevo enačbo, lahko izpeljemo: $i^{i}=$ $\left(e^{i \frac{\pi}{2}}\right)^{i}=e^{-\frac{\pi}{2}}$, iz česar seveda sledi, da je tudi $e^{-\frac{\pi}{2}}$ transcendentno število.

- Če je $\alpha=\sqrt{5}$ in $\beta=\frac{1+\sqrt{5}}{2}$ (zlati rez), so hipoteze izreka ponovno izpolnjene in sledi, da je $\sqrt{5}^{\beta}=5^{\frac{\beta}{2}}$ transcendentno število.

Izrek 4.3 lahko zapišemo še drugače:

IZREK 4.14 Naj bosta $\alpha$ in $\gamma$ neničelni algebraični števili in $\alpha \neq 1$. Potem je $\frac{\log \gamma}{\log \alpha}$ bodisi racionalno ali pa transcendentno število.

Dokaz Zgornji izrek je ekvivalenten Izreku 4.3. če nastavimo, da je $\beta=\frac{\log \gamma}{\log \alpha}$, iz česar potem sledi $\gamma=\alpha^{\beta}$.

Da pokažemo, da izrek 4.3 implicira izrek 4.14 , predpostavimo, da so hipoteze Izreka 4.14 izpolnjene, hkrati pa predpostavimo, da je $\beta=\frac{\log \gamma}{\log \alpha}$ algebraično število, a ne racionalno. Potem sledi po Izreku $4 \cdot 3(\alpha \neq 0,1, \beta$ je algebraično iracionalno število $)$, da je število $\gamma=\alpha^{\beta}$ transcendentno, kar pa je $\mathrm{v}$ nasprotju $\mathrm{z}$ našo predpostavko, da je $\gamma$ algebraično število.

Obratno bomo dokaz, da izrek 4.14 implicira izrek 4.3 izvedli s protislovjem. Privzemimo torej, da sta $\alpha \neq 0,1$ in $\beta$ algebraični števili in $\beta$ iracionalno število, ter da $\alpha^{\beta}$ ni transcendentno 
(torej je algebraično). Ker sta $\gamma=\alpha^{\beta}$ in $\alpha \neq 1$ algebraični, po Izreku 4.14 sledi, da je $\beta$ racionalno ali transcendentno. To pa je v nasprotju z začetno predpostavko, da je $\beta$ iracionalno algebraično število.

Izrek 4.14 implicira, da so logaritmi pozitivnih racionalnih števil (v bazi 10) bodisi racionalni ali pa transcendentni, kar lahko vidimo iz spodnje enakosti:

$$
\log _{10} r=\frac{\log r}{\log 10}
$$

Sedaj lahko izluščimo dodaten rezultat. Če je $r$ pozitivno racionalno število, ki ni oblike $10^{n}$, kjer je $n$ racionalno celo število, potem je $\log _{10} r$ transcendentno število. 


\section{Zaključek}

V okviru magistrske naloge smo spoznali dokaze iracionalnosti števil $\sqrt[n]{m}, e^{n}$ in $\pi^{2}$, kot tudi dokaze transcendentnosti števil $e$ in $\pi$ in nenazadnje tudi števil oblike $\alpha^{\beta}$. Dokaz transcendentnosti števila $\pi$ je najprej objavil Ferdinand Von Lindemann leta 1882, pomagal pa si je s številom $e^{a}$ in Eulerjevo identiteto $e^{i \pi}=-1$. Njegovo metodo je nato posplošil Karl Weierstrass, danes to poznamo kot Lindemann-Weierstrassov izrek, ki ima za posledico tudi transcendentnost števila $\pi$. Bralec je lahko tudi sam opazil, da je izmed vseh dokazov dokaz transcendentnosti števila $\pi$ najbolj poseben, saj se posluži elementarnih simetričnih polinomov, brez katerih dokaza ni mogoče izpeljati do konca. Bralec je lahko tudi opazil, da je v okviru magistrske večkrat prišla do izraza številska vrsta za število $e$.

Praktično vsi dokazi so potekali s protislovjem, poleg tega pa smo se v dokazih poslužili tudi pomožnih funkcij, preko katerih smo nato konstruirali celo število, ki je bilo po velikosti med 0 in 1, iz česar je potem izhajalo protislovje. Raziskovanje transcendentnih števil se je po dokazu Hilbertovega sedmega problema nadaljevalo z Alanom Bakerjem, ki je posplošil rezultat Gelfonda in Schneiderja in ki podaja spodnjo mejo linearnih kombinacij algebraičnih števil. Potemtakem Bakerjev izrek zagotovi transcendentnost števil oblike $\alpha_{1}^{\beta_{1}}, \ldots, \alpha_{n}^{\beta_{n}}$, kjer so $b_{i}$ iracionalna algebraična števila in so $h k r a t i ~ 1, b_{1}, \ldots, b_{n}$ linearno neodvisna nad racionalnimi števili, poleg tega pa so $a_{i}$ algebraična in niso 0 ali 1 . Več o Bakerjevih metodah in dokazih lahko bralec prebere v njegovi knjigi [1].

Do zdaj je bila dokazana transcendentnost naslednjih števil: $e, \pi, \log (2), e^{\sqrt{2}}$, $e^{\pi}, 2^{\sqrt{2}}, \Gamma\left(\frac{1}{4}\right)$, kjer je $\Gamma(x)$ dobro znana neelementarna funkcija gama. Vendar pa kljub temu še vedno ne vemo, ali so transcendentna tudi naslednja števila: $e+\pi, e \pi, \log (\pi), \pi^{e}, \Gamma\left(\frac{1}{5}\right), \zeta(3)$, kjer je $\zeta(s)$ spet dobro znana neelementarna funkcija Zeta. Vemo pa, da je vsaj eno izmed števil $e+\pi$ in $e \pi$ transcendentno število, kar lahko vidimo preko slednje enačbe:

$$
\begin{aligned}
(x-e)(x-\pi) & =0 \\
x^{2}-x(e+\pi)+e \pi & =0
\end{aligned}
$$

Če bi bili obe števili $e+\pi$ in $e \pi$ algebraični, potem bi to pomenilo, da sta $e$ in $\pi$ rešitvi polinoma $\mathrm{z}$ algebraičnimi koeficienti, kar pa je nemogoče, saj vemo, da sta $e$ in $\pi$ transcendentni števili. Z raziskovanjem je nadaljeval še Gregory Chudnovsky, ki je leta 1976 dokazal algebraično neodvisnost števil $\pi$ in $\Gamma\left(\frac{1}{4}\right)$, kot tudi algebraično neodvisnost števil $\pi$ in $\Gamma\left(\frac{1}{3}\right)$. Ta dejstva imajo za posledico transcendentnost števil $\Gamma\left(\frac{1}{4}\right)$ in $\Gamma\left(\frac{1}{3}\right)$.

Zgodba se nato nadaljuje leta 1996 še z Yurijem Nesterenkom, ki je dokazal algebraično neodvisnost števil $\Gamma\left(\frac{1}{4}\right), \pi$ in $e^{\pi}$, kot tudi algebraično neodvisnost števil $\Gamma\left(\frac{1}{3}\right), \pi$ in $e^{\pi \sqrt{3}}, \operatorname{kar}$ ima med drugim za posledico tudi, da sta števili $\pi$ in $e^{\pi}$ algebraično neodvisni. 


\section{Literatura}

[1] BAKER, A. Transcendental number theory. Cambridge University Press, London-New York, 1975 .

[2] BAKer, A., Wústholz, G. Logarithmic forms in Diophantine geometry, vol. 9 of New Mathematical Monographs. Cambridge University Press, Cambridge, 2007.

[3] Fraleigh, J. B. A first course in abstract algebra. Pearson Education India, 2003.

[4] Globevnik, J., Brojan, M. Analiza 1, vol. 25 of Matematični rokopisi. DMFA, 2016.

[5] MacHALE, D. 92.30 the well-ordering principle for n. The Mathematical Gazette 92, 524 (2008), 257-259.

[6] MarčEtrć, D. Transcendentnost nekaterih števil: diplomsko delo. [D. Marčetić], 1978. Bibliografija: str. 42.

[7] Niven, I. Irrational numbers. No. 11. Cambridge University Press, 2005.

[8] Olver, P. J. Applications of Lie groups to differential equations, vol. 107 of Graduate Texts in Mathematics. Springer-Verlag, New York, 1986.

[9] Pollard, H., Diamond, H. G. The Theory of Algebraic Numbers. Dover books on mathematics. Dover Publications, 1998.

[10] Slapar, M., Drinovec-Drnovšek, B., Prezelj-Perman, J. Osnove kompleksne analize. Pedagoška fakulteta, 2012. 